\title{
Virtual Simulation Analysis of Rigid-Flexible Coupling Dynamics of Shearer with Clearance
}

\author{
Hongyue Chen, ${ }^{1,2}$ Kun Zhang $\left(\mathbb{D},{ }^{1}\right.$ Mingbo Piao, ${ }^{1}$ Xin Wang $\left(\mathbb{D},{ }^{1}\right.$ \\ Jun Mao $\mathbb{1}^{1,},{ }^{1,2}$ and Qiushuang Song ${ }^{3}$ \\ ${ }^{1}$ School of Mechanical Engineering, Liaoning Technical University, No. 88, Yulong Road, Xihe District, Fuxin City, \\ Liaoning Province 123000, China \\ ${ }^{2}$ China National Coal Association, Dynamic Research for High-End Complete Integrated Coal Mining Equipment and \\ Big Data Analysis Center, No. 88, Yulong Road, Xihe District, Fuxin City, Liaoning Province 123000, China \\ ${ }^{3}$ China Coal Energy Company Limited (China Coal Energy), No. 1, Huangsi Street, Chaoyang District, Beijing City 100120, China
}

Correspondence should be addressed to Kun Zhang; zhangkunliaoning@163.com

Received 30 October 2017; Revised 4 February 2018; Accepted 20 February 2018; Published 4 April 2018

Academic Editor: Mario Terzo

Copyright (C) 2018 Hongyue Chen et al. This is an open access article distributed under the Creative Commons Attribution License, which permits unrestricted use, distribution, and reproduction in any medium, provided the original work is properly cited.

A model for virtual simulation analysis of the rigid-flexible coupling of a shearer has been developed with the objective of addressing problems associated with lifetime mismatch and low reliability of pin rows of a scraper conveyor and the corresponding support mechanism of a shearer. Simulations were performed using the experimental roller load as stimulus. Results of the analysis demonstrate that the vertical cutting force on the roller serves to reduce the load on the plane support plates during shearer cutting, and the force on the right plane support plate is considerably smaller compared to that on the left plane support plate along the direction of motion of the shearer. Owing to action of the roller-traction load, loads acting on the two guiding support plates increase significantly along the direction of shearer motion. Mechanical characteristics of the support mechanism were determined through experiments, and the accuracy of the virtual simulation model was verified. Simultaneously, mechanical characteristics of the shearer support mechanism were studied under varying pitch and roll angles. This study was performed to provide a base for analyzing the mechanical characteristics as well as optimizing the structural design of the shearer. Through fatigue-life analysis of the support plate and subsequent optimization of the support plate structure, the life of the guide support plate was found to have been extended by approximately 1.5 times.

\section{Introduction}

Coal reserves count as one of the most widely used energy resources in the world. Commonly used equipment in coal mining includes the shearer, scraper conveyor, and hydraulic support. Equipment and machinery employed in the mining of coal have been a subject of intense research in various countries in recent years. Efremenkov et al. [1] studied factors responsible for the deterioration of Russian coal mining equipment technology as well as the negative impact of coal mining on the environment. Simon et al. [2] investigated the reliability of the main transport system of the Svea coal mine in Svalbard, Norway, and compiled the equipment maintenance report for the year 2010 demonstrating an annual utilization of $96.44 \%$ of the six major conveyors. The report prescribed further improvement in equipment reliability to reduce the risk of failures. Korski et al. [3] evaluate the effectiveness and usefulness of mining machinery employed in the Polish hard coal industry through use of an OEE (Overall Equipment Effectiveness) indicator.

Shearers comprise mining equipment widely used at the face of a coal mine $[4,5]$, and the plane and guiding support plates constitute main connecting parts between the shearer and scraper conveyor. Performance of the guiding support plates directly determines the service life of the shearer and scraper conveyor [6].

Coal seam development inside a coal mine is usually characterized by a gradient that governs the roll and pitching angles of the working face. With changes in these roll and pitch angles, the force acting on the guiding support plates 
undergoes corresponding changes, thereby causing impact and abrasion between guiding support plates and the pin row. The pin row correspondingly produces a large reaction force on the guide hook of the guiding support plates. An extremely large magnitude of this force may result in failure of the guide hook or pin row, thereby affecting the stability and reliability of operation of the shearer and scraper conveyor [7]. In addition, during oblique cutting of a coal wall by means of a shearer, owing to line-shape bending of the scraper conveyor, the friction and impact forces acting between the inner side of the support mechanism and the scraper pin row undergo an increase, thereby resulting in cracking or pin breakage of the support mechanism $[8,9]$. Therefore, an understanding of the mechanical properties of the shearer and scraper conveyor is important while addressing the abovementioned issues concerning the support mechanism and pin damage.

Problems encountered during operation of mining machinery have been investigated in detail by engineers and researchers in the past. Zachura and Żuczek [10] developed an innovative Flextrack system capable of limiting the development of large pressing stresses between cooperating surfaces of the drive wheel and tooth gear (according to Hertz). Advanced toothed gear systems designed in this way enable one to overcome the horizontal and vertical inclinations of the conveyor route upon which the shearer moves. This, in turn, serves to increase the operational life of drive wheels, thereby significantly reducing the maintenance time under dangerous operating conditions. Chen et al. [11] devised a mechanical model representing the entire shearer assembly operating under the oblique cutting condition. They also derived and evaluated forces of interaction acting between the support mechanism and two pin rows of a coal mining machine by means of finite element analysis. Additionally, they determined the fatigue risk point for a scraper pin row through fatigue-life analysis of support plates and scraper pin row. Liu and Dai [12] used the comprehensive method of preestimation and state judgment to develop the mechanical model of a shearer. Chen et al. [13] proposed use of a mechanics-based model for the entire shearer assembly developed using the deformation compatibility equation. The loads acting on left and right driving rollers, evaluated through experiments, were provided as input to the model, and the stepwise discriminant method was used to solve the model numerically, thereby obtaining the loads acting on the walking support part during the cutting operation of the shearer. Liu et al. [14] established a mechanical model and state equation for the shearer based on structural parameters associated with a coal mining machine, the corresponding operating parameters, and the roll angle of a coal seam. The superposition algorithm was used to numerically solve the model. Shen et al. [15] suggested, analyzed, and verified improvements in the operation of support plates of a shearer assembly using the finite element method. The improved support plates were applied to actual operation in a coal mine, and good results were achieved. Lu [16] used the finite element method to analyze the operation of shearer support plates. The concentrated stress caused by virtual constraints was removed, maximum stress acting at the support plates was obtained, and the stress concentration in support plates was evaluated and analyzed to increase their strength. A GCr13 gasket was added to improve the wearing resistance of the support plates. Chen et al. [17] used the description of stiffness and damping of plane support plates in accordance with Hertz contact theory and established a 7-degreeof-freedom dynamic model of the shearer based on the Lagrange dynamics equation. They used a numerical method to solve for vibration characteristics of the shearer model under different haulage speeds. Zhang et al. [18] derived the relationship between the direction of the supporting force on each support plate and coefficient matrix of the static equation of the shearer; the equation was solved using the Gauss-Jordan method. Liu and Tian [19] used the least square and generalized inverse methods to solve for the force change law of the support plates of a shearer under different operating conditions. Wang [20] used the virtual prototype technology for meshing the shearer driving wheel and scraper conveyor pin row for simulation. They used two different theories to calculate contact stresses for the shearer driving wheel and scraper conveyor pin row. Chen et al. [21] devised a nonlinear model to describe the action between the shearer driving wheel and scraper pin row under clearance using gear meshing. They used the Kulun friction model to describe the sliding friction between the supporting mechanism of the shearer and scraper conveyor. The Newmark method was used to solve the equation. Zhou et al. [22] made us of a virtual prototype developed using the ANASYS/LS_DYNA technology to simulate and analyze dynamic meshing characteristics of an involute shearer walking mechanism and type III pin rail. Zhou et al. [23] established a dynamic model of the traction part of a shearer. Concurrently, the dynamic reliability evaluation of a transmission system under load was studied based on the sequential statistic theory. Liu and Luo [24] established a test platform for the walking mechanism of the traction part a shearer. The mechanism was studied experimentally using the 3-point test method, and rules of vibration governing the walking mechanism were obtained. Liu et al. [25] analyzed wear failure forms of the support plates of a shearer and optimized the support plate performance using plasma cladding with Cr4MnTi. Hong and Gong [26] used a reciprocating pin on a disc of $\mathrm{Fe}$ (21 wt.\%)-Cr (5 wt.\%)-B alloy under the dry sliding condition and performed the friction wear test through use of a wear-testing machine. They performed a comparative analysis with conventional support plate manufacturing materials and observed that the wear resistance of support plate manufacturing materials can be much improved through use of their proposed approach. The above extant studies have primarily focused on theoretical analysis and have not performed a combined experimentalnumerical analysis.

The proposed study adopts the virtual prototype technology to establish a rigid-flexible coupling model whilst considering the test load on the shearer drum as stimulus. The model includes line shape of the middle trough of a scraper conveyor. Impact characteristics of the shearer guiding support plates and pin row clearance, contact-friction characteristics of the plane support plates and middle trough, meshing characteristics of the driving wheel and pin row, flexible characteristics of the shearer rocker arm, and, lastly, 
mechanical characteristics of the guiding and plane support plates have been simulated and analyzed in this study. In addition, the results obtained via simulations have been verified through experiments, and underlying mechanisms of the guiding and plane support plates have been examined. This provides a basis for structural optimization and lifespan prediction of the walking part of the shearer as well as a basis for investigating mechanical properties of the entire shearer assembly under various operating conditions.

\section{Scraper Conveyor Line Shape}

Under actual operating conditions, there exists a relative 6-degree-of-freedom pose between two adjacent middle troughs owing to uneven fluctuations in the coal floor and errors in the movement of the middle trough. To facilitate construction of a simulation model of the scraper conveyor, it was assumed that the bottom surface of the roadway below the scraper was rigid, and the effect of external forces on the middle trough posture was negligible. The lineshape function of the scraper conveyor could, therefore, be expressed as

$$
\text { SHAPE }=\left[\begin{array}{llll}
W_{1} & W_{2} & \cdots & W_{n}
\end{array}\right] .
$$

The center of the first middle trough was coordinated as the coordinate origin, as such, $W_{i}, i=1 \cdots n, i$ represent coordinate exchanges for the first middle trough.

Dynamic characteristics of the shearer when performing the linear cutting operation have been investigated. Owing to relatively small magnitudes of the rotation angles between adjacent central troughs under actual operating conditions, their influence on the shape of the scraper line was neglected in order to simplify the model. The position of each middle trough could then be determined based on its actual working position.

\section{The Proposed Virtual Model and Corresponding Boundary Conditions}

3.1. Model Simplification and Hypothesis. The MG500/1180 shearer and SGZ1000/1050 scraper models were considered as research objects. The Pro/E CAD software was used to design central models of the shearer and scraper conveyor, which were then saved in the step entity format in RecurDyn. Because the size of a fully mechanized mining face is considerably large and since there exist several parts in a coal mining machine, we applied the following processing steps and hypotheses to the model prior to simulation.

(1) To reduce the size of the simulation model, threedimensional models of the shearer and 11 parts of the middle trough of the scraper conveyor were developed.

(2) In the shearer model, all parts except the left and right rockers were designed as rigid bodies.

(3) No model for the transmission system was established; only its quality attributes were set in the rocker arm. In addition, only quality attributes of the hydraulic and electriccontrol systems were set within the fuselage.

(4) Regardless of the influence of elastic deformation of the hydraulic rod placed between walking mechanisms of the left and right shearers and electric-control box, the electriccontrol box was integrated within the housing of the left and right shearer walking mechanisms and considered part of the fuselage.

(5) Other than the connection clearance between the guiding support plates and pin row and that between adjacent middle troughs, all clearances in other parts of the model were assumed to be zero.

(6) Any friction caused by relative motion between pairs of surfaces was neglected, except for the guiding support plates, plane support plates, and scraper conveyor contact friction.

(7) It is assumed that there exists no relative motion between the two middle troughs during shearer operation.

(8) The coal face roll and pitch angles $(\partial, \beta)$ were assumed zero.

(9) The walking direction of the shearer was represented by $Z$, while the converse direction of the vertical scraper conveyor was represented by $Y$.

3.2. Flexible Treatment of Rocker Arm. Flexible treatment of the rocker arm was executed in RecurDyn using FFlex and accomplished by means of the following steps.

(1) The Mesher grid division tool in the FFlex module was used to divide the rocker arm.

(2) The maximum and minimum grid sizes were set as 50 and $10 \mathrm{~mm}$, respectively.

(3) Solid4 was selected as the entity unit type, and unit material properties corresponding to those of isotropic steel were set.

(4) The inner wall of the mounting hole at the joint between the rocker arm and fuselage pin shaft was defined as Patch 1. It serves to connect the fuselage pin shaft between the flexible surface and cylindrical contact. Correspondingly, the inner wall of the mounting hole at the joint between the rocker arm and lifting cylinder pin shaft was defined as Patch 2, thereby serving to connect the lifting cylinder pin shaft between the flexible surface and cylindrical contact. The rocker and drum connected to the surface were considered rigid surfaces. Slave and master nodes were created at end faces of the rocker and roller connections to ensure efficient transmission of the roller force to the rocker arm.

3.3. Motion Constraints. Motion constraints of connections between components in the virtual model are listed in Table 1.

3.4. Definition of Contact. The shearer was supported by left and right guiding support plates as well as left and right plane support plates on the middle trough of the scraper conveyor, and the walking operation was accomplished by coordinated operation of the driving wheel and pin row. During the combined walking and cutting process of the shearer, collision and friction exist between plane support plates and middle trough, guiding support plates and pin row, and the driving wheel and pin row. In the RecurDyn virtual model, the contact between the driving wheel and pin row has been defined to be of the solid-solid type, while that between lower end faces of plane support plates and 
TABLE 1: Motion constraints.

\begin{tabular}{llc}
\hline Part 1 & Part 2 & Constraint \\
\hline Fuselage & Left and right rocker arm pin shafts & Fixed pair \\
Left and right rocker arm pin shafts & Left and right rocker arm & Rigid-flexible surface contact \\
Left and right rocker arm & Left and right rollers & Revolute pair \\
Fuselage & Left and right lifting cylinder rod pin shafts & Revolute pair \\
Left and right rocker arm & Left and right lifting cylinder pin shafts & Rigid-flexible surface contact \\
Left and right lifting cylinder rod & Left and right lifting cylinder & Translating pair \\
Fuselage & Left and right guiding support plate pin shafts & Fixed pair \\
Left and right plane support plate pin shafts & Left and right guiding support plates & Revolute pair \\
Fuselage & Left and right plane support plates pin shafts & Fixed pair \\
Left and right plane support plate pin shafts & Left and right plane support plates & Revolute pair \\
Left and right guiding support plate pin shafts & Left and right driving wheels & Revolute pair \\
Pin row & Scraper middle trough & Fixed pair \\
Scraper middle trough & Ground & Fixed pair
\end{tabular}

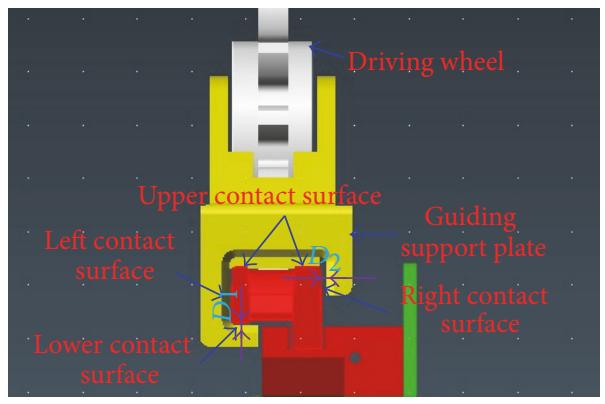

(a)

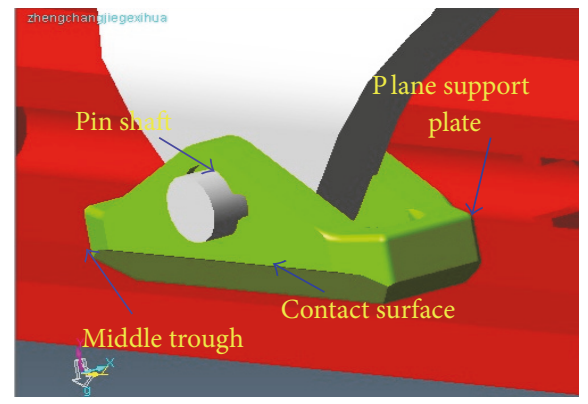

(b)

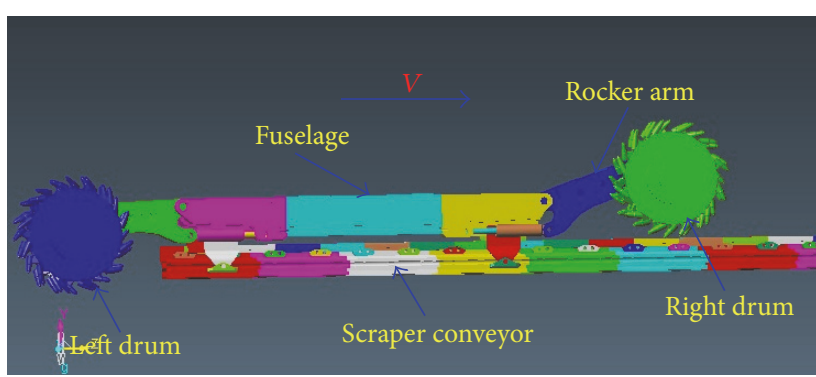

(c)

FIGURE 1: Definition of various contact surfaces. (a) The guiding support plate contacts the pin row. (b) The plane support plate contacts the middle trough. (c) The proposed rigid-flexible coupling model.

middle trough has been defined to belong to the surfacesurface type. In addition, contact between the upper, lower, left, and right sides of the guiding support plates and those of the pin row is also of the surface-surface type, as depicted in Figure 1. In Figure 1, D1 and D2 represent gap values between guiding support plates and the pin row in the vertical and horizontal directions, respectively; values of $D 1$ and $D 2$ are 18 and $26 \mathrm{~mm}$, respectively.

In RecurDyn, calculation of contact forces is based on

$$
f_{n}=k \delta^{m 1}+c \frac{\dot{\delta}}{|\dot{\delta}|}|\dot{\delta}|^{m 2} \delta^{m 3},
$$

where $k$ denotes the contact stiffness coefficient, $c$ represents damping coefficient, $m 1, m 2$, and $m 3$ represent the contact rigidity index, damping, and dent indices, respectively, and $\delta$ denotes the penetration depth.

Friction is calculated by setting appropriate values for the static $\left(\mu_{s}\right)$ and dynamic $\left(\mu_{d}\right)$ friction coefficients.

The abovementioned parameters are to be set in accordance with the relevant size and material of the shearer and scraper conveyor. Through several simulations, values of $m 1$, $m 2$, and $m 3$ were determined as $1.02,1.1$, and 1.33 , respectively. Values of other parameters are listed in Table 2 [27].

3.5. Definition of Load. During shearer operation in the linear cut state, the definition of load primarily includes the three-direction resistance of cutting picks of the left and right drums and the corresponding drum torque. In 
TABLE 2: Contact surface parameters.

\begin{tabular}{|c|c|c|c|c|}
\hline Contact position & $k$ & $c$ & $u_{s}$ & $u_{d}$ \\
\hline Driving wheel and pin row & $3.5 \times 10^{9}$ & $7.2 \times 10^{5}$ & 0.21 & 0.18 \\
\hline Plane support plates and middle trough end face & $1.34 \times 10^{11}$ & $2.6 \times 10^{6}$ & 0.21 & 0.18 \\
\hline Guiding support plates and upper contact surface of the pin row & $8.2 \times 10^{10}$ & $1.25 \times 10^{6}$ & 0.21 & 0.18 \\
\hline Guiding support plates and lower contact surface of the pin row & $4.2 \times 10^{10}$ & $6.2 \times 10^{5}$ & 0.21 & 0.18 \\
\hline Guiding support plates and left contact surface of the pin row & $7.5 \times 10^{10}$ & $1.01 \times 10^{6}$ & 0.21 & 0.18 \\
\hline Guiding support plates and right contact surface of the pin row & $1.02 \times 10^{11}$ & $2.15 \times 10^{6}$ & 0.21 & 0.18 \\
\hline
\end{tabular}

TABLE 3: Parameters of interest for drum-type shearer.

\begin{tabular}{lccccc}
\hline Drum parameters & Roller width $(\mathrm{mm})$ & Hub diameter $(\mathrm{mm})$ & Drum diameter $(\mathrm{mm})$ & Helix angle $\left(^{\circ}\right)$ & Number of blades \\
\hline Value & 1000 & 680 & 2000 & 25 & 3 \\
\hline
\end{tabular}

this study, the experimental load on the drums was used as stimulus. Structural parameters of interest to the drum shearer used during experiments conducted in this study are listed in Table 3. A typical test system for evaluating the threedirection resistance of cutting picks is depicted in Figure 2(a). A wireless strain acquisition module is installed at the end of the screw blade of the drum (the tail close to the rocker side), as depicted in Figure 2(a). A welding strain gage is installed at the end of the cutting pick, and the adjacent wireless strain acquisition module is accessed through a wire. The roller torque is measured by means of an idler axle pin sensor installed on the sixth idler axle, and all data are collected using the wireless strain acquisition module.

Once the system begins to collect relevant data, the wireless strain acquisition module stores the collected data and transmits the same by means of a wireless gateway-based transmission facility. The data signals are finally transmitted to a computer via a wireless communication converter [28, 29]. The sampling frequency is $100 \mathrm{~Hz}$, and approximately 50000 data points are collected. Data processing has been optimized in order to efficiently handle the large amount of data involved, and average values of parameters are considered after every 25 sampling points. Over the duration of the cutting operation of the shearer (approximately 50 s), 2000 resistance load values, each for the left and right drums, are selected, as depicted in Figures 2(b) and 2(c).

3.6. Definition of Driver. The proposed model was able to achieve a stable walking speed of $4 \mathrm{~m} / \mathrm{min}$ at an elapsed time of $3 \mathrm{~s}$ after initiation of the shearer operation. Driving speeds of the left and right driving wheels could be determined based on the diameter of the dividing circle of the shearer driving wheel. According to the reference diameter of shearer drive wheel is $0.815 \mathrm{~m}$, and the speeds of the front and the rear drive wheel are set to step(time, $0,0 \mathrm{~d}, 3,9.38 \mathrm{~d})+$ step(time, 3, $0 \mathrm{~d}, 53,0 \mathrm{~d}$ ). Driving speeds of the left and right drums are obtained as follows: $\operatorname{step}($ time $, 0,0 \mathrm{~d}, 3,168 \mathrm{~d})+$ step(time, 3, $0 \mathrm{~d}, 53,0 \mathrm{~d}$ ).

The coal cutting height was set as $3 \mathrm{~m}$. In accordance with the size of the shearer's structure, elongations of the left and right lifting cylinders of the shearer could be determined. As the proposed model was created using Pro/E, and the cutting height was set as $3 \mathrm{~m}$, the extension was set to 0 in RecurDyn.

The simulation exercise was completed in $53 \mathrm{~s}$, the first three seconds of which constitute the initial or start-up stage of the machine. During operation in this phase, the working resistance of the two drums is zero. The normal cutting operation of the shearer lasted $50 \mathrm{~s}$ between 3 and $53 \mathrm{~s}$. Loads were imposed in accordance with the data depicted in Figures 2(b) and 2(c). Drum loading data generated over the entire duration of the simulation were collated and imported into RecurDyn to generate curves corresponding to $F_{x 1}, F_{x 2}$ (right and left drum axial load), $F_{y 1}, F_{y 2}$ (right and left drum cutting load), $F_{z 1}, F_{z 2}$ (right and left drum traction load), and $T_{1}$ and $T_{2}$ (right and left drum torque load). The above curves were loaded using the AKISPL function. The complete simulation model is depicted in Figure 1(c).

\section{Simulation Results and Analysis}

4.1. Analysis of Forces Acting on Plane Support Plate Pin Shafts. Time histories of forces acting along the $Y$ and $Z$ directions on the support plate pin shaft in the left plane are depicted in Figures 3(a) and 3(b), respectively. During the start-up phase of the shearer (0-3s), no load was applied on the drums, and the average load on the pin shaft in the along direction was measured as $22.52 \mathrm{t}$. During the period of actual cutting operation (3-53 s), loads were applied on the drums, and the average load $\left(F_{\mathrm{HLY}}\right)$ during this phase was measured to be approximately $19.74 \mathrm{t}$, implying a decrease of $2.78 \mathrm{t}$ compared to the start-up phase. The mean value of the load acting on the pin shaft along the $Z$ direction $\left(F_{\mathrm{HLZ}}\right)$ was approximately $-4.21 \mathrm{t}$ during the start-up phase; its corresponding value during the actual cutting operation was $1.99 \mathrm{t}$, that is, a decrease of $2.22 \mathrm{t}$.

Time histories of forces acting along the $Y$ and $Z$ directions on the support plate pin shaft in the right plane are depicted in Figures 3(c) and 3(d), respectively. Average forces acting along the $Y$ direction $\left(F_{\mathrm{HRY}}\right)$ measured $18.09 \mathrm{t}$ and $7.32 \mathrm{t}$, respectively, during the start-up and actual cutting phases of the shearer, thereby demonstrating a decrement of $10.77 \mathrm{t}$ during the actual cutting phase. Corresponding 


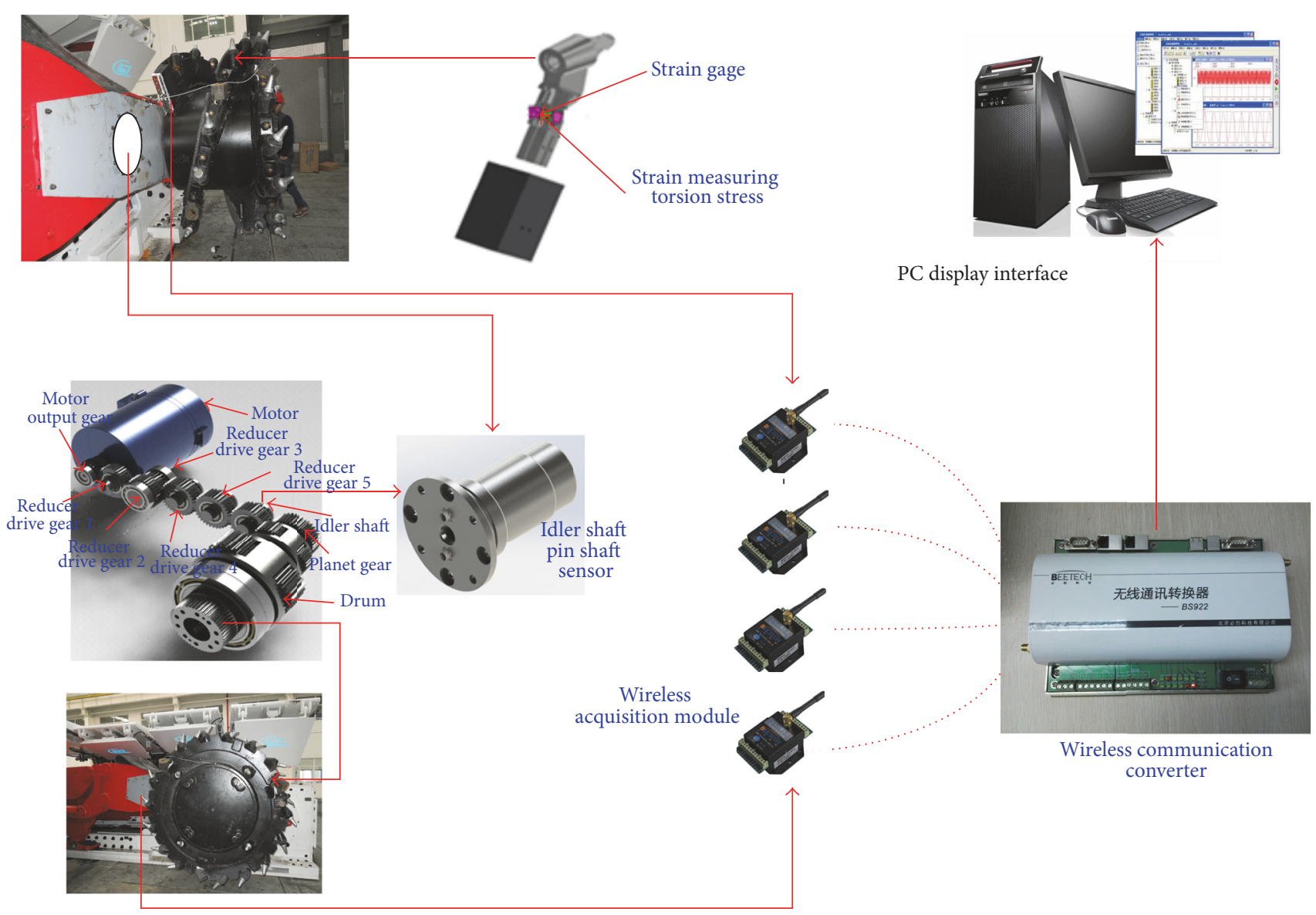

(a)

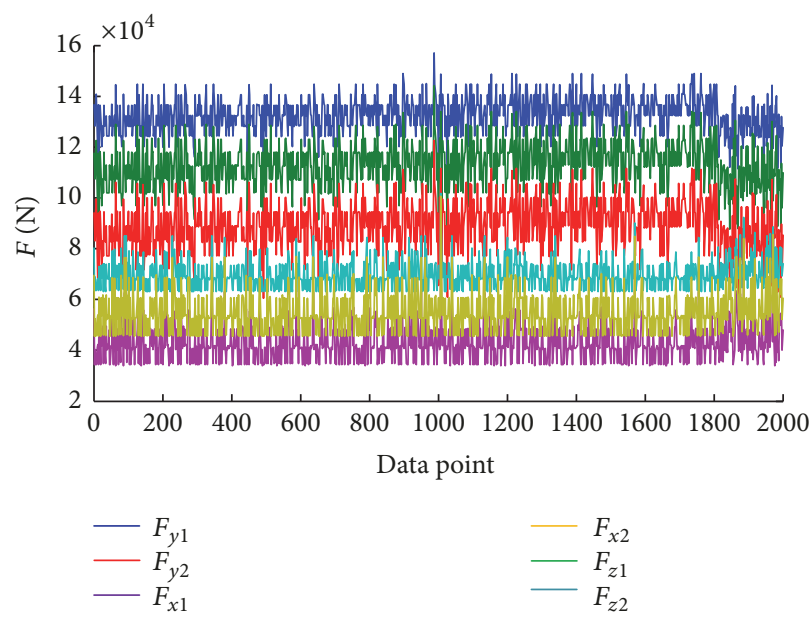

(b)

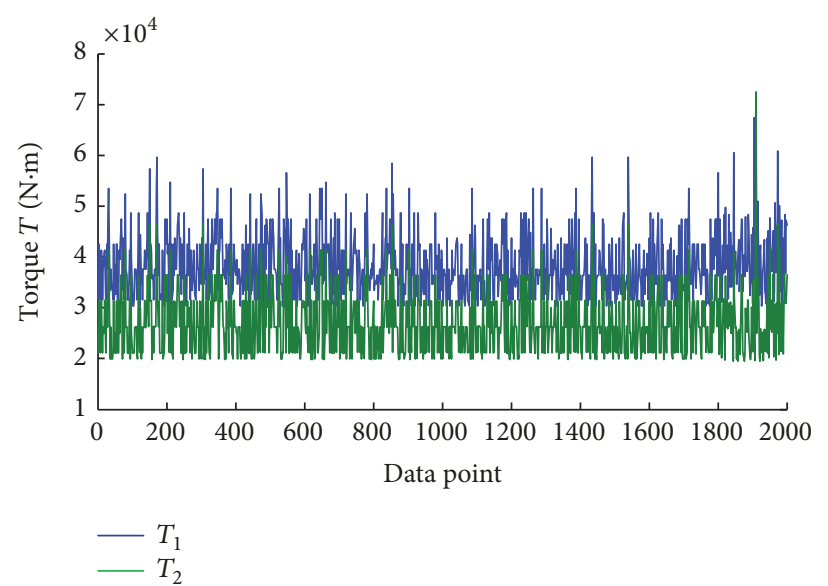

(c)

Figure 2: Test system and test load. (a) System layout for evaluating three-direction resistance of cutting picks and corresponding drum torque. (b) Result for three-direction resistance load of cutting picks. (c) Result for drum torque load.

values of the average force acting along the $Z$ direction $\left(F_{\mathrm{HRZ}}\right)$ measured $-3.7 \mathrm{t}$ during the start-up phase and $-1.81 \mathrm{t}$ during the actual cutting phase, thereby demonstrating a relative decrease of $1.89 \mathrm{t}$.

As depicted in Figure 3, forces acting on the left and right plane support plate pin shafts during the actual cutting operation of the shearer drum are considerably lower compared to those acting during the start-up phase of the machine. This is because at the instant when the shearer is set in operation, the load acting on the drum along the $Y$ direction is zero. At this time, gravitational and inertial forces acting on the shearer are borne by the left and right plane 


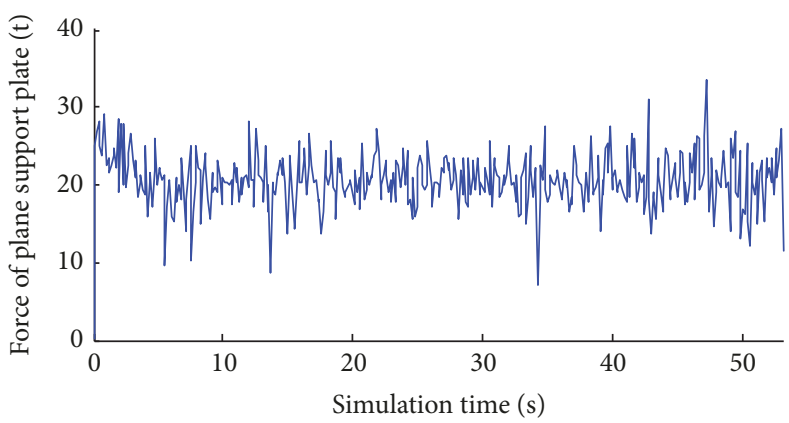

(a)

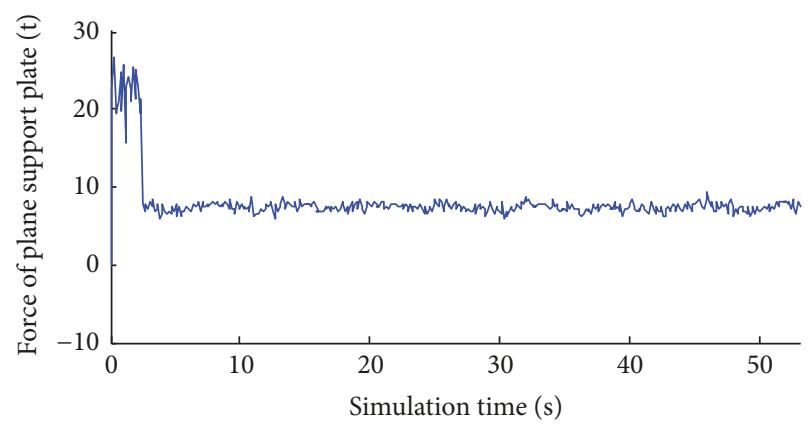

(c)

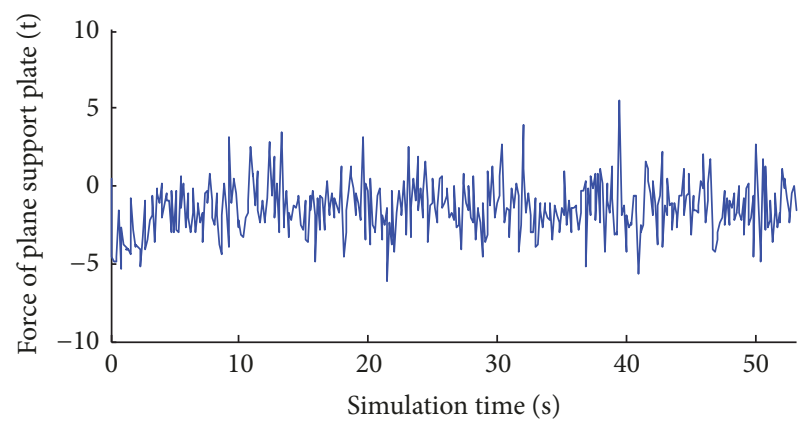

(b)

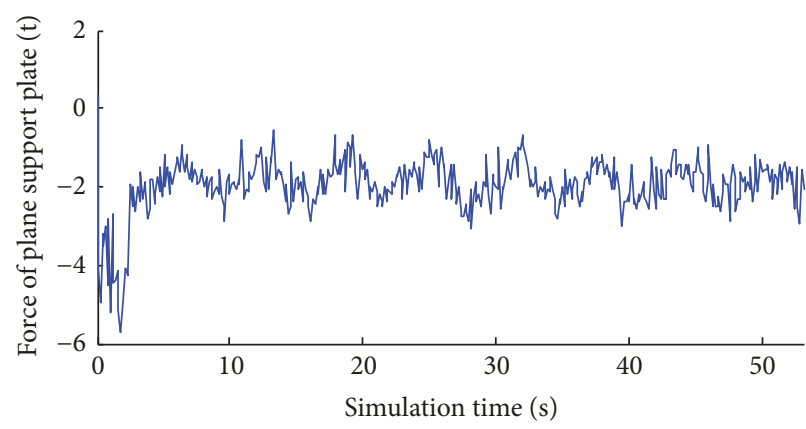

(d)

Figure 3: Time histories of forces acting on plane support plate pin shafts. (a) Force along the $Y$ direction on the left plane support plate pin shaft, (b) force along the $Z$ direction on the left plane support plate pin shaft, (c) force along the $Y$ direction on the right plane support plate pin shaft, and (d) force along the $Z$ direction on the right plane support plate pin shaft.

and guiding support plates. During the actual cutting phase of the left and right drums, owing to directions of the imposed cutting load, $F_{y 1}$ and $F_{y 2}$ assume positive values, and their respective directions are the same as that of the support load acting on the plane support plate along the $Y$ direction. Thus, the left and right drums tend to cut off loads along the vertical direction, thereby offsetting the load acting on a part of the plane support plate along the $Y$ direction. This, in turn, causes loads acting on the left and right plane support plate pin shafts to decrease. The load acting on the two plane support plate pin shafts along the $Z$ direction primarily represents the friction that occurs between the plane support plates and middle trough. Thus, the trend observed for the two pin shafts in terms of forces acting along the $Z$ direction is identical to that observed along the $Y$ direction.

A comparison of Figures 3(a), 3(b), 3(c), and 3(d) demonstrates that the force acting along the $Y$ direction on the left side of the plane support plate pin shaft is larger compared to that acting on its right side. This is because the drum on the right with respect to the walking direction of the coal machine is used to cut the top coal and rocks during the simulation process. The lifting angle of the right rocker arm is, therefore, larger. In this case, the cutting and traction loads and the cutting resistance torque acting on the right drum cause the shearer to produce a backward overturning moment, due to which the right side of the shearer has a tendency to lift upwards. Consequently, the force on the right of the plane support plate pin shaft along the $Y$ direction is relatively small.
4.2. Analysis of Forces Acting on Guiding Support Plate Pin Shafts. Time histories of forces acting along the $Y$ and $Z$ directions on the left guiding support plate pin shaft are depicted in Figures 4(a) and 4(b), respectively. The average force along the $Y$ direction $\left(F_{\mathrm{DLY}}\right)$ measured approximately $9.35 \mathrm{t}$ during the start-up phase of the shearer $(0-3 \mathrm{~s})$ and approximately $3.95 \mathrm{t}$ during the actual cutting phase, thereby demonstrating a decrease of $5.4 \mathrm{t}$ between phases. In addition, the force follows a negative load trend curve. This is because during the actual cutting phase of the shearer, when the drum load fluctuates and connection between middle troughs is not flat, contact occurs between the guiding support plates and upper and lower surfaces of the pin row. The lower surface of the pin row causes collision, and the force on the pin shaft acting along the $Y$ direction therefore changes. The average force acting along the $Z$ direction $\left(F_{\mathrm{DLZ}}\right)$ measured approximately $11.48 \mathrm{t}$ during the start-up phase and $28.07 \mathrm{t}$ during the actual cutting phase, that is, an increase of $16.59 \mathrm{t}$ between phases.

Time histories of forces acting along the $Y$ and $Z$ directions on the right guiding support plate pin shaft are depicted in Figures 4(c) and 4(d), respectively. The average force along the $Y$ direction $\left(F_{\mathrm{DRY}}\right)$ measured approximately $8.31 \mathrm{t}$ during the start-up phase and approximately $4.81 \mathrm{t}$ during the actual cutting phase, thereby indicating a decrease of $3.5 \mathrm{t}$ between phases. The reason behind negative values being observed in the trend curve, depicted Figure 4(c), is essentially the same as that for corresponding values observed in the case of the left guiding support plate pin shaft. The average force 


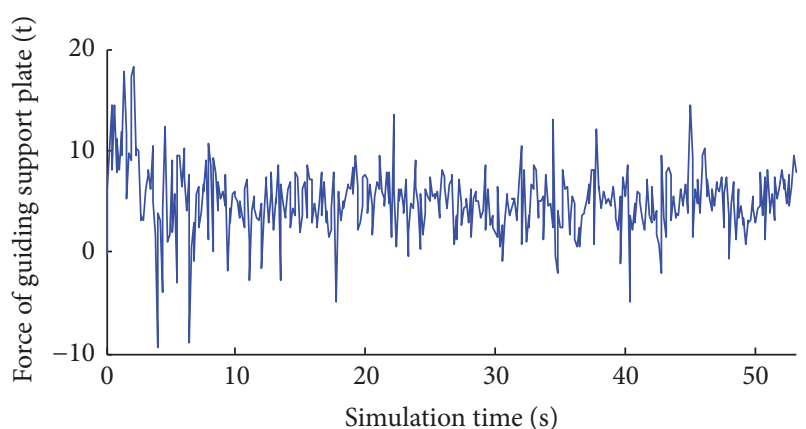

(a)

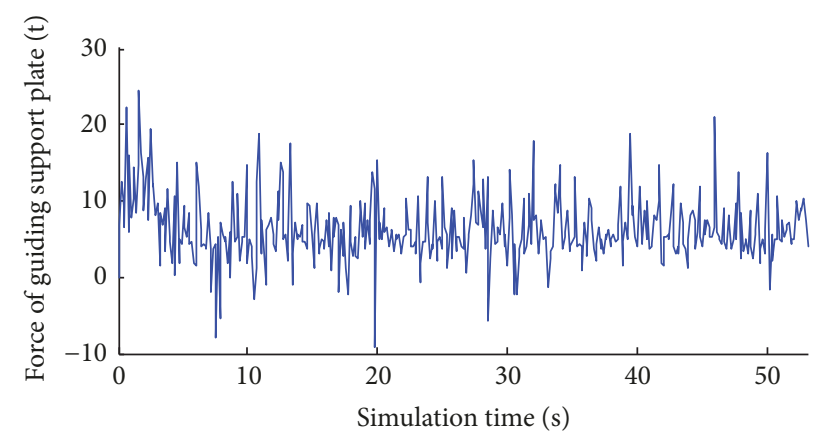

(c)

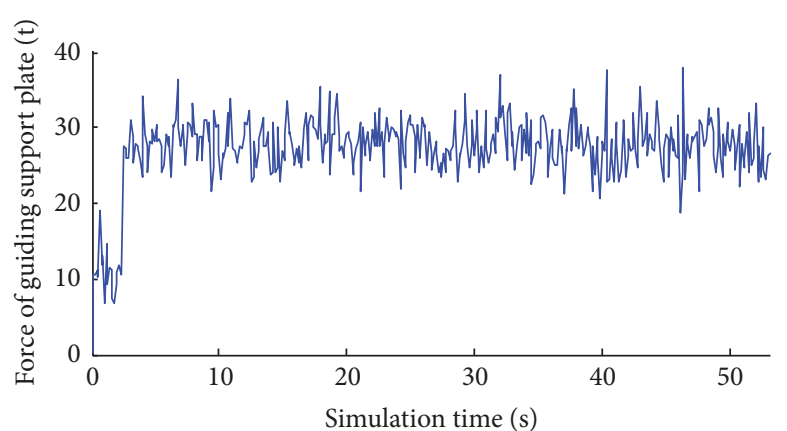

(b)

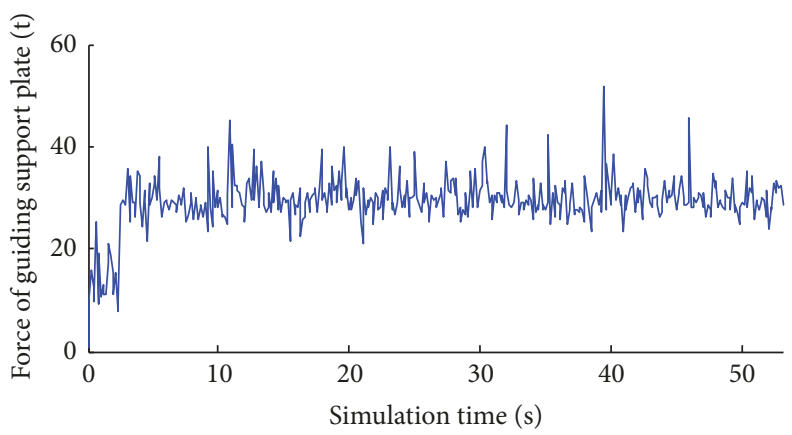

(d)

FIGURE 4: Time histories of forces acting on guiding support plate pin shafts. (a) Force along the $Y$ direction on the left guiding support plate pin shaft, (b) force along the $Z$ direction on the left guiding support plate pin shaft, (c) force along the $Y$ direction on the right guiding support plate pin shaft, and (d) force along the $Z$ direction on the right guiding support plate pin shaft.

along the $Z$ direction $\left(F_{\mathrm{DRZ}}\right)$ measured approximately $13.58 \mathrm{t}$ during the start-up phase and approximately $28.05 \mathrm{t}$ during the cutting phase implying an increase of $14.47 \mathrm{t}$ between phases.

An analysis of the time histories depicted in Figures 4(a), 4(b), 4(c), and 4(d) demonstrates that when the left and right drums perform the cutting operation, forces acting on the left and right guiding support plate pin shafts along the $Y$ direction reduce to the support load; however, corresponding loads on the two pin shafts increase along the $Z$ direction. This is because directions of the cutting loads, $F_{y 1}$ and $F_{y 2}$, on the left and right drums are aligned along that of the supporting load on the pin shaft along the $Y$ direction. Concurrently, directions of cutting loads, $F_{z 1}$ and $F_{z 2}$, acting on the left and right drums are opposite to that of the supporting load on the pin shaft along the $Z$ direction. Thus, when the drums are set into the cutting operation, loads on the two pin shafts decrease along the $Y$ direction and increase along the $Z$ direction.

\section{Experimental Verification}

The Key Laboratory of the National Energy Center Experimental Center for Coal Mining Machinery Equipment Research and Development was deemed appropriate as the experimental site. At this site, an experimental coal wall could be constructed using a $1: 1$ scale ratio to simulate a corresponding coal wall in an actual underground coal mine. The main coal wall comprised coarse and fine coal aggregate, while water, cement, and a water reducer were used as additives. The coal aggregate was extracted from the Xinwen region of the Shandong province. Particle size of the coarse coal aggregate ranged between 5 and $50 \mathrm{~mm}$ with a natural apparent density of $1,331 \mathrm{~kg} / \mathrm{m}^{3}$. The fine coal aggregate comprised particles measuring $0.2-5 \mathrm{~mm}$, water extracted from groundwater sources in the Xinwen region, composite cement (Tangshan shield Jidong PC32.5), and FND super water reducing agent (manufactured by Jinan Shanghai Chemical Technology Co., Ltd.) capable of achieving waterreduction rates of the order of $18-28 \%$. The density of the fine aggregate was approximately $3,090 \mathrm{~kg} / \mathrm{m}^{3}$. Mixture ratios of the simulated composite coal wall are listed in Table 4.

An experiment coal wall was poured specially, and the length of it is $70 \mathrm{~m}$, the width is 3 meters, and the thickness is 4 meters. The consistent coefficient of the coal wall was tested to be $f_{3}$ one month after the coal wall had hardened.

As previously mentioned, the MG500/1180 shearer and SGZ1000/1050 scraper conveyor were used. The experimental setup employed in this study was capable of performing online measurements of the mechanical properties of coal; it could accurately measure 3-D loads acting on shearer picks as well as loads acting on pin shafts of the plane and guiding support plates. To ensure safety of operation and reliability during the experimental process, a wireless signal transmission system was employed. Position of installation and experimental setup of each sensor employed in the experiment are depicted in Figure 5. During the experiment, the shearer was set to operate at a cutting speed of $4 \mathrm{~m} / \mathrm{min}$, 
TABLE 4: Constituent material mixture ratios for simulated composite coal wall.

\begin{tabular}{ccccc}
\hline & \multicolumn{2}{c}{ Simulated coal wall mixture ratios $\left(\mathrm{kg} / \mathrm{m}^{3}\right)$} & \\
Coarse aggregate & Fine aggregate & Water & Cement & Water reducing agent \\
\hline 950 & 600 & 200 & 260 & 1.69 \\
\hline
\end{tabular}

TABLE 5: Contact surface parameters of sensors employed in this study.

\begin{tabular}{cccccccc}
\hline Accuracy & Safe load & $\begin{array}{c}\text { Temperature } \\
\text { range }\end{array}$ & $\begin{array}{c}\text { Zero } \\
\text { temperature } \\
\text { drift }\end{array}$ & $\begin{array}{c}\text { Sensitivity } \\
\text { temperature } \\
\text { drift }\end{array}$ & $\begin{array}{c}\text { Bridge } \\
\text { impedance }\end{array}$ & $\begin{array}{c}\text { Sensor } \\
\text { material }\end{array}$ & $\begin{array}{c}\text { Supply } \\
\text { voltage }\end{array}$ \\
\hline $0.02 \% \mathrm{Fs}$ & $150 \% \mathrm{Fs}$ & $-20-65^{\circ} \mathrm{C}$ & $\begin{array}{c}<0.05 \% \\
\mathrm{Fs} / 10^{\circ} \mathrm{C}\end{array}$ & $\begin{array}{c}<0.03 \% \\
\mathrm{Fs} / 10^{\circ} \mathrm{C}\end{array}$ & $700 \Omega$ & $40 \mathrm{CrNiMO}_{4}$ & $12-30 \mathrm{~V}(\mathrm{DC})$ \\
\hline
\end{tabular}

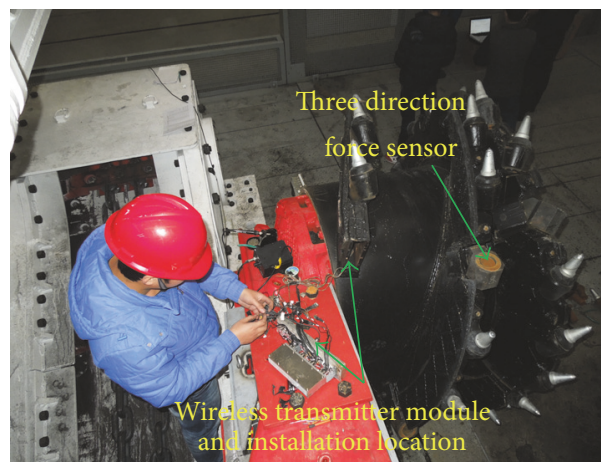

(a)

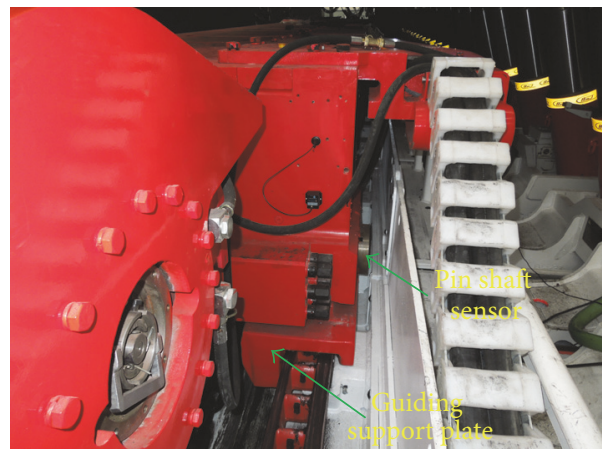

(c)

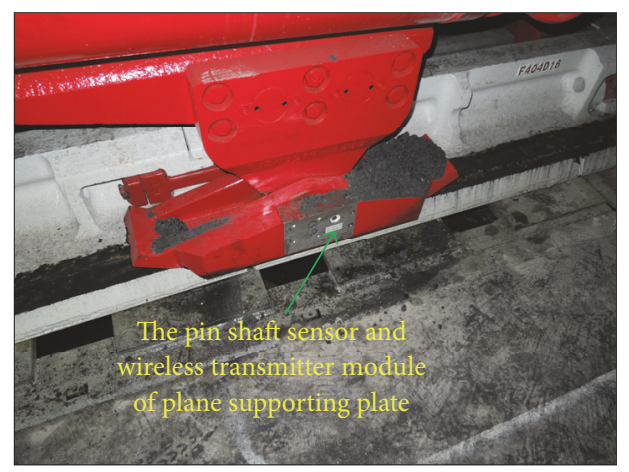

(b)

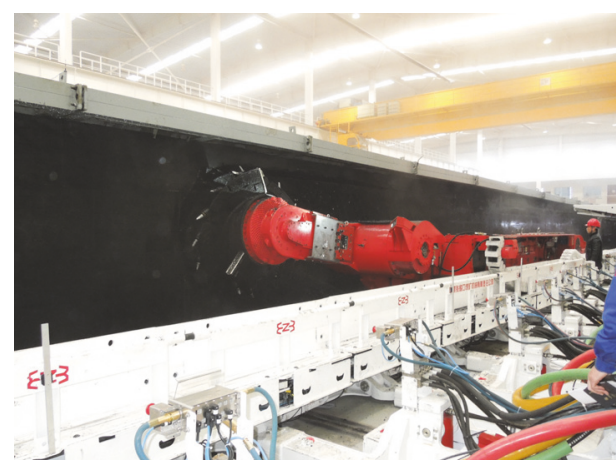

(d)

FIGURE 5: Sensor installation and experimental setup. (a) Test system of shearer pick, (b) plane support plate pin shaft, (c) guiding support plate pin shaft, and (d) experimental field.

the cutting depth of the drum was set at $500 \mathrm{~mm}$, and the roller speed was $28 \mathrm{rpm}$.

The SG403/404 pin shaft sensors installed on the plane and guiding support plates were produced by Jiangsu Donghua Testing Technology Co., Ltd. Primary technical specifications of these sensors are listed in Table 5.

Calibration of the pin shaft sensor prior to their installation was necessary in order to ensure accuracy of measurement during force tests of the supporting mechanism of the shearer. During the calibration process, it was ensured that changes in the range of loading values did not assume large values, and values of the loads imposed were gradually increased in intervals of $10 \mathrm{kN}$. Tests were repeated under identical loading conditions, thereby improving the precision of the measurement system. The level of precision was then further improved by averaging out all measured values. Tables 6 and 7 list calibrated values for pin shaft sensors installed on the plane and guiding support plates and measuring loads acting along the $Y$ and $Z$ directions.

In accordance with values listed in Table 6, a quadratic curve-fitting equation for forces acting along $Y$ and $Z$ directions on the plane support plate pin shaft may be deduced as

$$
\begin{aligned}
F_{Y}= & 2.242 \times 10^{-6} x^{3}-1.862 \times 10^{-4} x^{2}+3.605 \\
& \times 10^{-2} x+4.071 \times 10^{-4},
\end{aligned}
$$


TABLE 6: Calibrated values of sensor output corresponding to forces acting on plane support plate pin shaft along the $Y$ and $Z$ directions.

(a) Calibrated values along $Y$ direction

\begin{tabular}{lcccc}
\hline Loading value $(\mathrm{kN})$ & 0 & 10 & 20 & 30 \\
\hline Output signal $(\mathrm{mV} / \mathrm{V})$ & 0.0001 & 0.3458 & 0.6631 & 0.9762 \\
\hline
\end{tabular}

(b) Calibrated values along $Z$ direction

\begin{tabular}{lcccc}
\hline Loading value $(\mathrm{kN})$ & 0 & 10 & 20 & 30 \\
\hline Output signal $(\mathrm{mV} / \mathrm{V})$ & 0.0001 & 0.3538 & 0.6885 & 1.0181 \\
\hline
\end{tabular}

TABLE 7: Calibrated values of sensor output corresponding to forces acting on guiding support plate pin shaft along the $Y$ and $Z$ directions.

(a) Calibrated values along $Y$ direction

\begin{tabular}{lcccc}
\hline Loading value $(\mathrm{kN})$ & 0 & 10 & 20 & 30 \\
\hline Output signal $(\mathrm{mV} / \mathrm{V})$ & 0.0001 & 0.3122 & 0.6328 & 0.9456 \\
\hline
\end{tabular}

(b) Calibrated values along $Z$ direction

\begin{tabular}{lcccc}
\hline Loading value $(\mathrm{kN})$ & 0 & 10 & 20 & 30 \\
\hline Output signal $(\mathrm{mV} / \mathrm{V})$ & 0.0001 & 0.3122 & 0.6394 & 0.956 \\
\hline
\end{tabular}

$$
\begin{aligned}
F_{Z}= & 1.358 \times 10^{-6} x^{3}-1.234 \times 10^{-4} x^{2}+3.639 \\
& \times 10^{-2} x+2.643 \times 10^{-4} .
\end{aligned}
$$

In accordance with values listed in Table 7, a quadratic curve-fitting equation for forces acting along $Y$ and $Z$ directions on the guiding support plate pin shaft may be deduced as

$$
\begin{aligned}
F_{Y}= & -9.417 \times 10^{-7} x^{3}+4.793 \times 10^{-5} x^{2}+3.098 \\
& \times 10^{-2} x-2.043 \times 10^{-4}, \\
F_{Z}= & -1.092 \times 10^{-6} x^{3}+6.721 \times 10^{-5} x^{2}+3.092 \\
& \times 10^{-2} x-4.471 \times 10^{-4} .
\end{aligned}
$$

Time histories of forces acting along $Y$ and $Z$ directions on the left and right plane support plate pin shafts are depicted in Figure 6. Comparison of Figures 6(a) and 6(b) indicates that forces acting on the left plane support plate pin shaft suffer considerable fluctuations. The force acting along the $Y$ direction on the left plane support plate pin shaft was found to be considerably larger compared to that acting on the right plane support plate pin shaft. This result is similar to the one obtained via simulations. A comparison of the results obtained via simulation and experiments is provided in Table 8 , and the values demonstrate good agreement between the two results. The minimum error (approximately $2.79 \%$ ) was observed when measuring the force acting along the $Y$ direction on the right plane support plate pin shaft.

Similarly, the maximum error (approximately 16.3\%) was observed when estimating the force acting along the $Z$ direction on the left plane support plate pin shaft. The above errors are believed to be caused by the fact that the friction coefficient for the simulation model has a fixed value; this, however, is not the case during actual experiments. Also, the plane support plates were placed closer to the coal wall during the experiment. As a result, the cutting coal or dust was compacted on the side of the middle slot by the right plane support plate in the walking direction, thereby creating a dust layer, which creates a lubrication effect. Existence of the dust layer reduces the coefficient of friction between the plane support plates and central trough. As a result, the measured force on the left pin along the $Z$ direction is smaller compared to the corresponding value obtained via simulation.

Time histories of forces acting along $Y$ and $Z$ directions on the left and right guiding support plate pin shafts are depicted in Figure 7. A comparison of the four figures indicates that forces acting along $Y$ and $Z$ directions on the left and right guiding support plate pin shafts demonstrate fluctuations similar to the plane support plate pin shaft cases considered above.

A comparison of average values of these forces obtained via simulation and experimental measurements is presented in Table 9. The maximum load error (approximately $10.83 \%$ ) was observed when estimating the force along $Y$ direction on the right pin shaft. The simulation values are found to demonstrate reasonable agreement with experimental results.

Comparison between simulation-based and experimentally derived cumulative load frequencies along the $Y$ direction on plane and guiding support plate pin shafts is depicted in Figure 8(a). As can be seen in the figure, $52.9 \%$ simulation data and $78.6 \%$ experimental data obtained for the right guiding support plate lie in the range of 8-13t. Similarly, $51.7 \%$ simulation data and $54.25 \%$ experimental data for the left guiding support plate lie in the range of $8-13 \mathrm{t}$. In the same way, $94.45 \%$ simulation data and $94.2 \%$ experimental data for the right plane support plate lie in the range of 13-18 $\mathrm{t}$. Lastly, $46.75 \%$ simulation data and $84.95 \%$ experimental data for the left plane support plate lie in the range of 23-28t. A similar comparison of cumulative load frequencies for forces acting along the $Z$ direction is depicted in Figure $8(\mathrm{~b})$. As seen, $75.9 \%$ simulation data and $75.4 \%$ experimental data for 


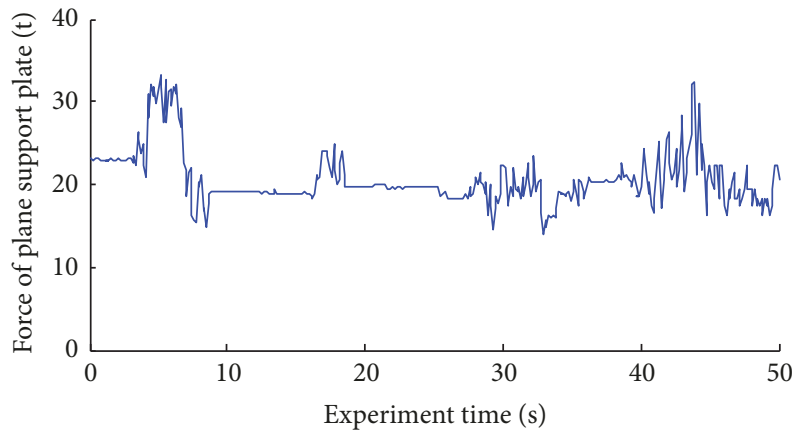

(a)

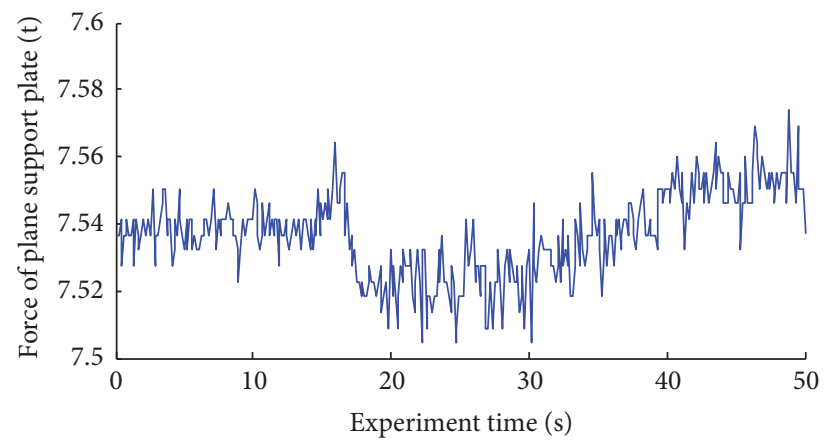

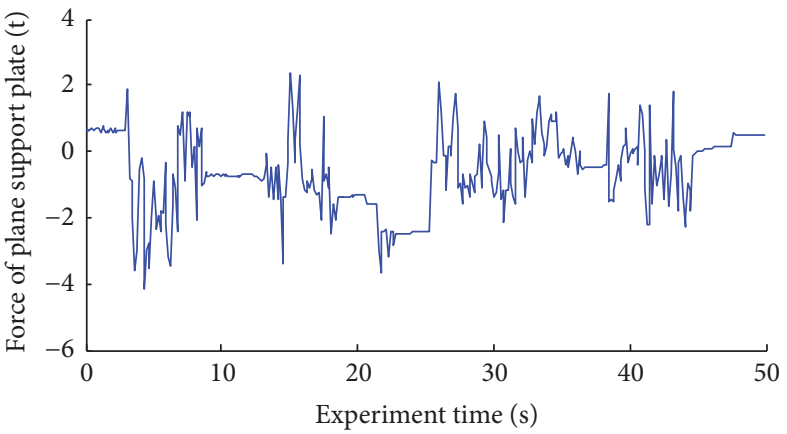

(b)

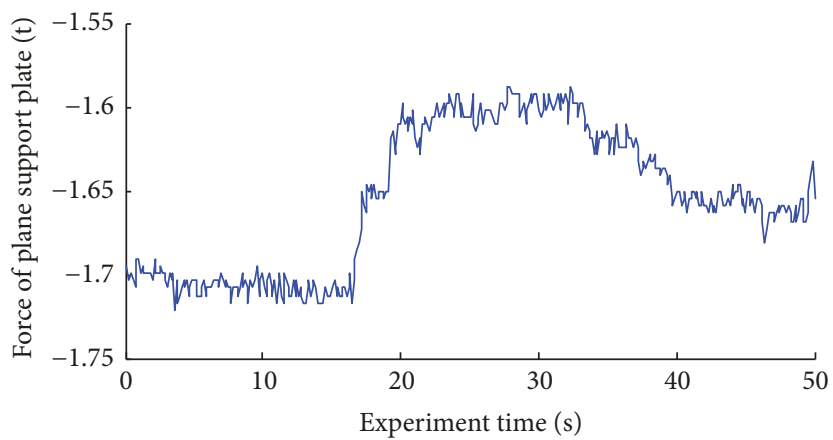

Figure 6: Time history of forces acting along $Y$ and $Z$ directions on plane support plate pin shafts. (a) Force along $Y$ direction on the left plane support plate pin shaft, (b) force along $Z$ direction on the left plane support plate pin shaft, (c) force along $Y$ direction on the right plane support plate pin shaft, and (d) force along $Z$ direction on the right plane support plate pin shaft.

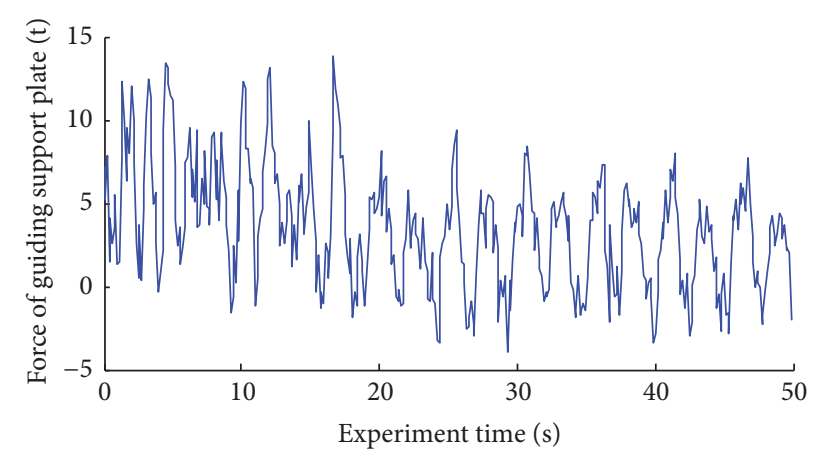

(a)

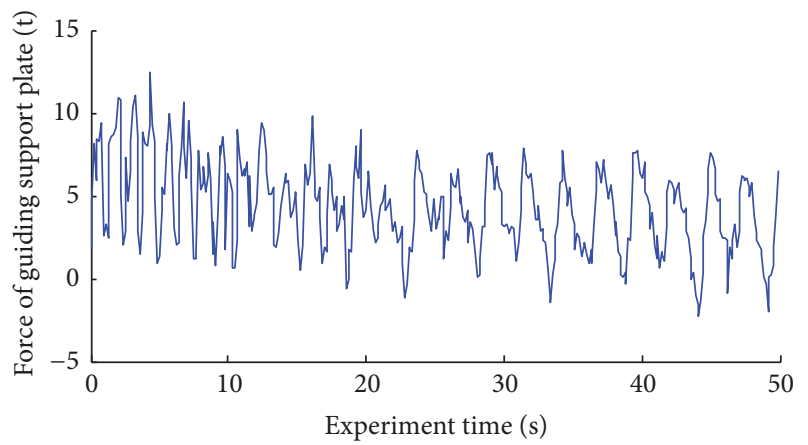

(c)

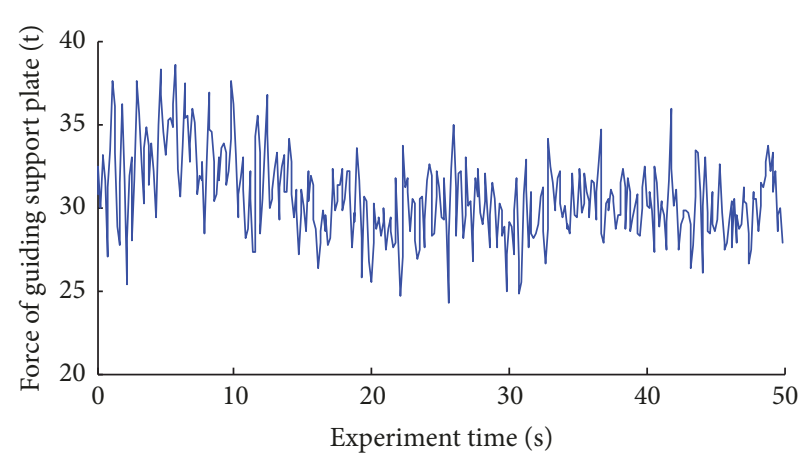

(b)

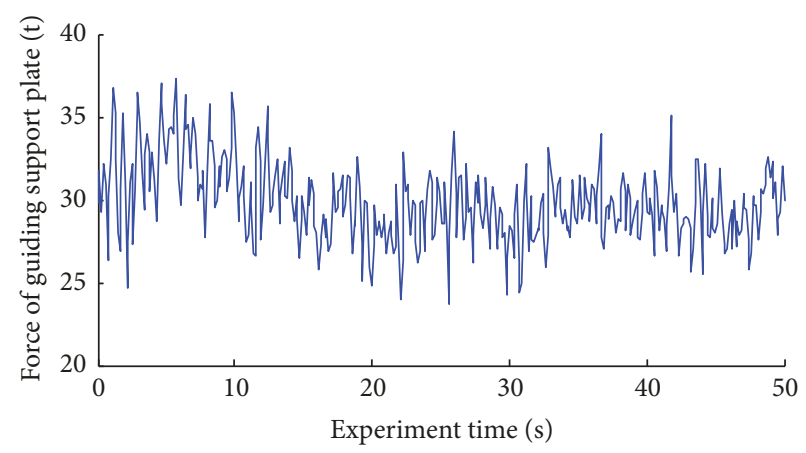

(d)

Figure 7: Time history of forces acting along $Y$ and $Z$ directions on guiding support plate pin shafts. (a) Force along $Y$ direction on left guiding support plate pin shaft, (b) force along $Z$ direction on left guiding support plate pin shaft, (c) force along $Y$ direction on the right guiding support plate pin shaft, and (d) force along $Z$ direction on the right guiding support plate pin shaft. 
TABLE 8: Comparison of forces acting on plane support plate pin shafts.

\begin{tabular}{lcccc}
\hline & $F_{\mathrm{HLY}}(\mathrm{t})$ & $F_{\mathrm{HLZ}}(\mathrm{t})$ & $F_{\mathrm{HRY}}(\mathrm{t})$ & $F_{\mathrm{HRZ}}(\mathrm{t})$ \\
\hline Simulation value/t & 19.74 & -1.99 & 7.32 & -1.81 \\
Experimental value/t & 20.62 & -1.71 & 7.53 & -1.62 \\
\hline
\end{tabular}

TABLE 9: Comparison of forces acting on guiding support plate pin shafts.

\begin{tabular}{lcccc}
\hline & $F_{\text {DLY }}(\mathrm{t})$ & $F_{\text {DLZ }}(\mathrm{t})$ & $F_{\text {DRY }}(\mathrm{t})$ & \\
\hline Simulation value/t & 3.96 & 28.07 & 4.81 & $F_{\text {DRZ }}(\mathrm{t})$ \\
Experimental value/t & 3.92 & 30.66 & 4.34 & 28.05 \\
\hline
\end{tabular}

the right guiding support plate lie within the $28-33 \mathrm{t}$ range; $77.05 \%$ simulation data and $66.5 \%$ experimental data for the left guiding support plate lie within the $28-33$ t range; $94.4 \%$ simulation data and $94.68 \%$ experimental data for the right plane support plate lie within the 3-8t range; lastly, $93.45 \%$ simulation data and $87.35 \%$ experimental data for the left plane support plate lie within the $3-8 \mathrm{t}$ range. The above analysis demonstrates the similarity between distribution laws for the simulation-based and experimentally obtained data.

Based on the operating speed of the shearer $(v=$ $4 \mathrm{~m} / \mathrm{min})$, drive wheel diameter $(d=0.815 \mathrm{~m})$, and number of teeth $(z=18)$, the drive wheel rotation frequency could be calculated as $f_{n}=v / 60 \pi d=0.0261 \mathrm{~Hz}$, while the engaging frequency between the drive wheel and pin row could be defined as $f_{m}=z f_{n}=0.4698 \mathrm{~Hz}$. Figure 9 depicts comparison between amplitude-frequency curves plotted using data obtained via simulation and experiments with regard to the plane support plate. In Figures 9(a) and 9(b), peak amplitude-frequency response values of $0.9453,1.443,2.83$, and $4.229 \mathrm{~Hz}$, respectively, correspond to frequency doublings of 2, 3, 6, and 9 with respect to the drive wheel engaging frequency. Similarly, in Figures 9(c) and 9(d), peak amplitude-frequency response values of $0.2385,0.4678$, 0.9453 , and $1.144 \mathrm{~Hz}$ correspond to frequency doublings of $0.5,1,2$, and 2.5 with respect to the drive wheel engaging frequency. This implies that variation in the engaging stiffness between the drive wheel and pin row is a major factor causing load variations on the plane support plate.

Figure 10 depicts comparison between amplitude-frequency response curves plotted using data obtained via simulation and experiments with regard to the guiding support plate. In Figures 10(a) and 10(b), the peak amplitudefrequency response values of $0.9453,1.443,2.83$, and $4.229 \mathrm{~Hz}$ correspond to frequency doublings of 2, 3, 6, and 9 with respect to the drive wheel engaging frequency. Similarly, in Figure 10(c), peak amplitude-frequency response values of $0.9453,1.8916$, and $4.229 \mathrm{~Hz}$ correspond to frequency doublings of 2, 4, and 9 with respect to the drive wheel engaging frequency. Lastly, in Figure 10(d), peak amplitude-frequency response values of $0.4678,1.443,2.348$, and $4.229 \mathrm{~Hz}$ correspond to frequency doublings of $1,3,5$, and 9 with respect to the drive wheel engaging frequency. This implies that variation in the engaging stiffness between the drive wheel and pin row is a major factor causing load variations on the guiding support plate.
Through comparison of the curves depicted in Figures 9 and 10, representing data obtained via simulation and experiment, it could be concluded that within a frequency range $2 \mathrm{~Hz}$, peak values of the amplitude-frequency response corresponding to experimental data are larger. However, within frequency ranges that exceed $2 \mathrm{~Hz}$, peak values of the amplitude-frequency response corresponding to data obtained via simulation are larger. Also, variation trends for the two curves are nearly coincident; this implies that the proposed simulation model is accurate up to a significant extent.

\section{Analysis of Forces Acting on Shearer Support Plate Pin Shafts under Different Pitching and Roll Angles}

Pitch and roll angles are generated on the working face of a coal mine owing to restrictions imposed by underground mining conditions. Considerable variations in the magnitude of these angles cause significant variations in the stresses induced in the support plate structures, which is an important concern. In the proposed study, with use of MG500/1180 shearer, the range of adaptation with respect to the overhand mining angle was $0-45^{\circ}$ and that with respect to the underhand stopping angle was $-45-0^{\circ}$. The roll angle towards the guiding support plate was found to be positive, and the range of adaptation with respect to the roll angle was $0-15^{\circ}$. The roll angle towards the plane support plate was negative, and the corresponding range of adaptation with respect to the roll angle was $-15-0^{\circ}$. Therefore, based on the proposed rigid-flexible coupling dynamics model, changes in the pitch and roll angles were affected via changes in the direction of gravity forces. In accordance with the previously described simulation steps, the model was simulated under different pitch and roll angles, and the mean forces on the support plate pin shafts under different pitch and roll angles were obtained, as depicted in Figure 11.

Figure 11(a) depicts changes in the mean force acting along the $Z$ direction on the plane and guiding support plates during overhand mining at pitch angles of $0-45^{\circ}$ degrees and underhand stopping at pitch angles of $-45-0^{\circ}$. The roll angle was maintained constant for this case. As observed from the figure, with increase in the overhand pitch angle from $0^{\circ}$ to $45^{\circ}$, the mean value of the force acting on the left guiding support plate increases from $29.825 \mathrm{t}$ to $34.23 \mathrm{t}$, while 


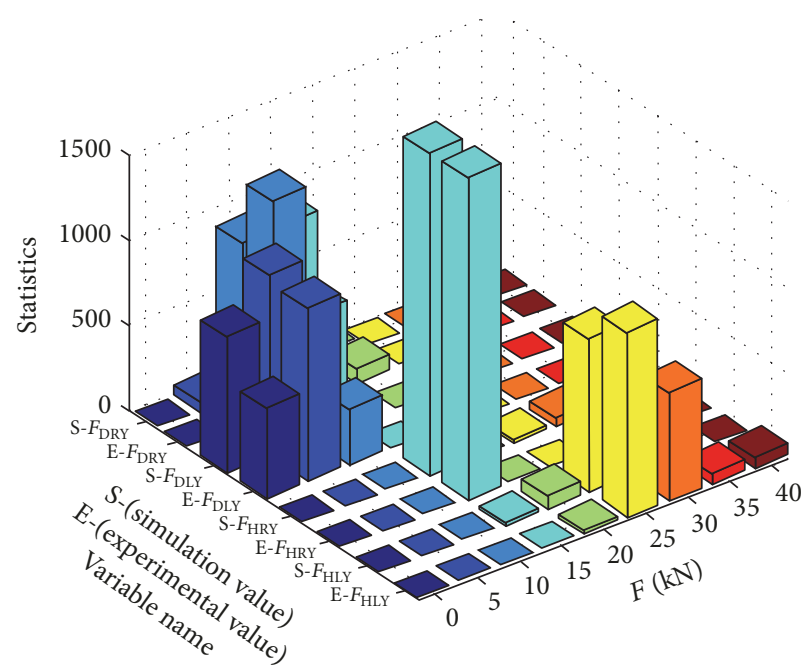

(a)

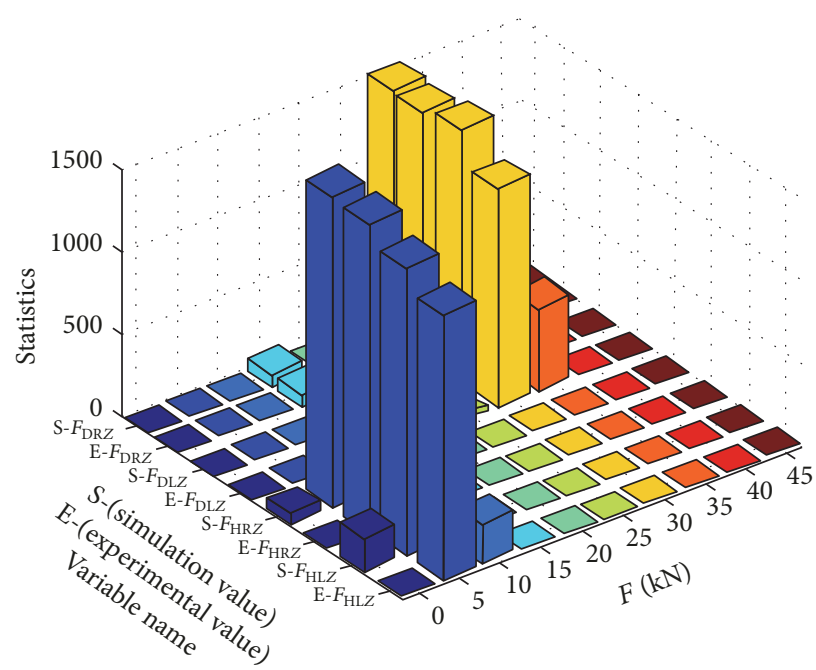

(b)

FIGURE 8: Comparison between simulation and experimentally obtained cumulative load frequencies along $Y$ and $Z$ directions. (a) Cumulative load frequency along $Y$ direction and (b) cumulative load frequency along $Y$ direction.

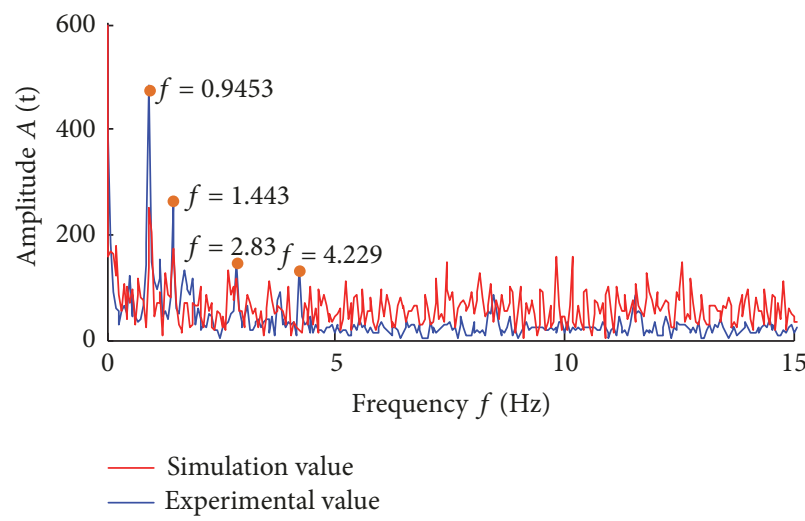

(a) Load of left plane support plate along the $Y$ direction

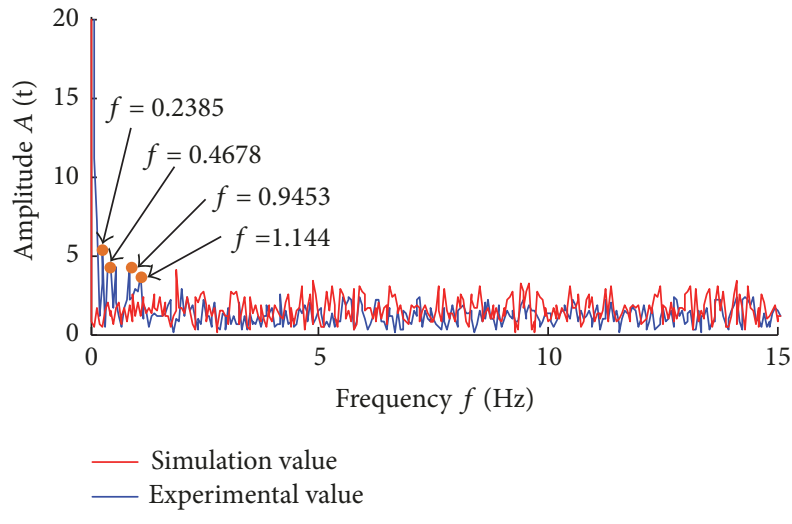

(c) Load of right plane support plate along the $Y$ direction

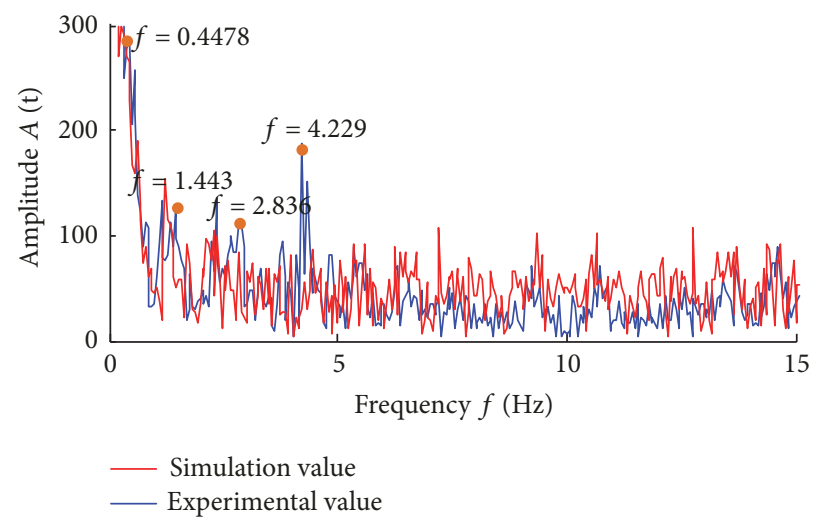

(b) Load of left plane support plate along the $Z$ direction

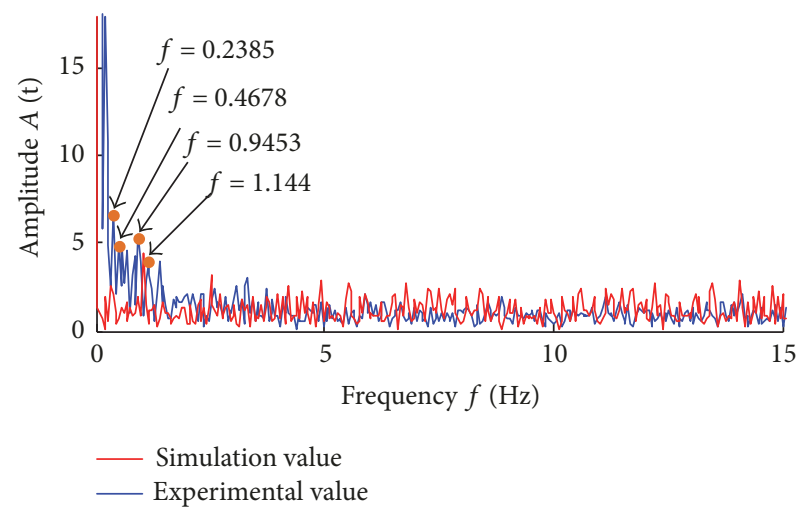

(d) Load of right plane support plate along the $Z$ direction

FIGURE 9: Amplitude-frequency response curves for the plane support plate.

that on the left plane support plate decreases from $-1.85 \mathrm{t}$ to $-5.62 \mathrm{t}$. Simultaneously, the mean force acting on the right guiding support plate decreases from $28.44 \mathrm{t}$ to $26.63 \mathrm{t}$, while that acting on the right plane support plate increases from
$-1.635 \mathrm{t}$ to $-0.62 \mathrm{t}$. In addition, as the underhand stopping angle increases from $-45^{\circ}$ to $0^{\circ}$, the mean force acting on the left guiding support plate increases from $25.13 \mathrm{t}$ to $29.825 \mathrm{t}$, while that acting on the left plane support plate decreases 


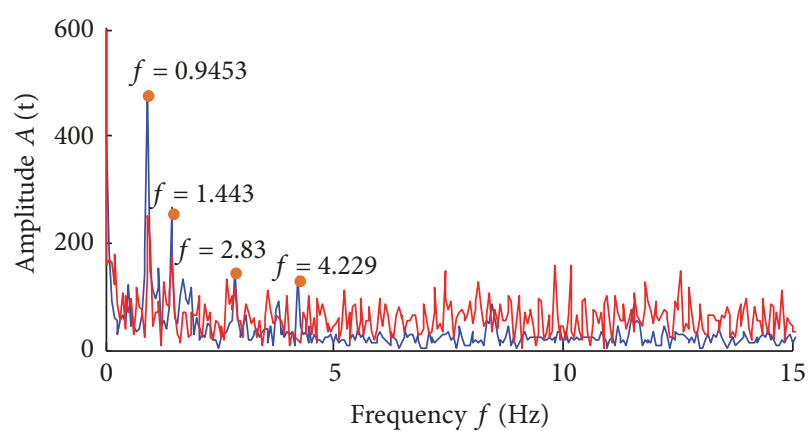

- Simulation value

Experimental value

(a) Load of left guiding support plate along the $Y$ direction

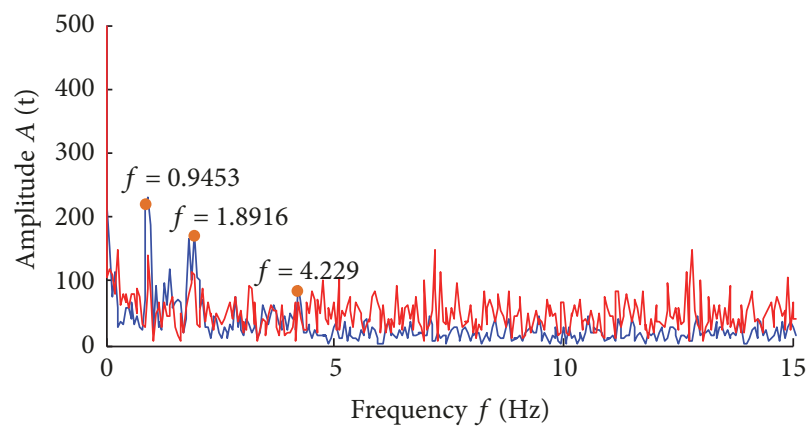

_ Simulation value

_ Experimental value

(c) Load of right guiding support plate along the $Y$ direction

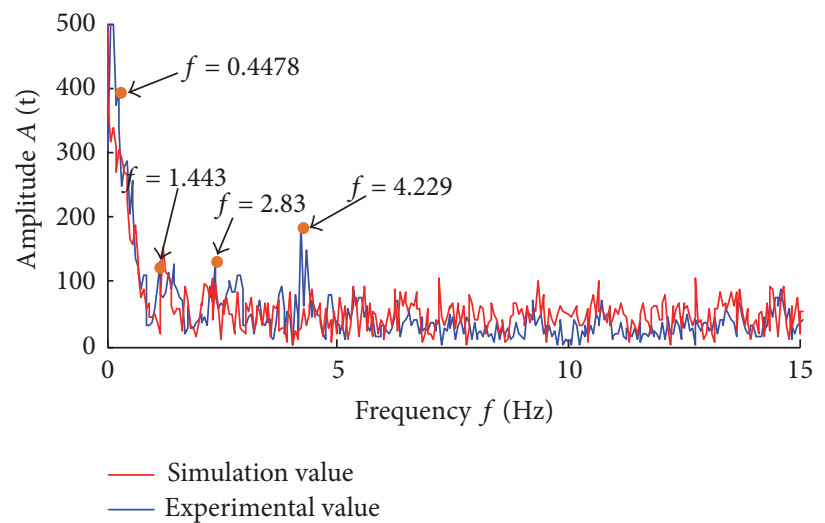

(b) Load of left guiding support plate along the $Z$ direction

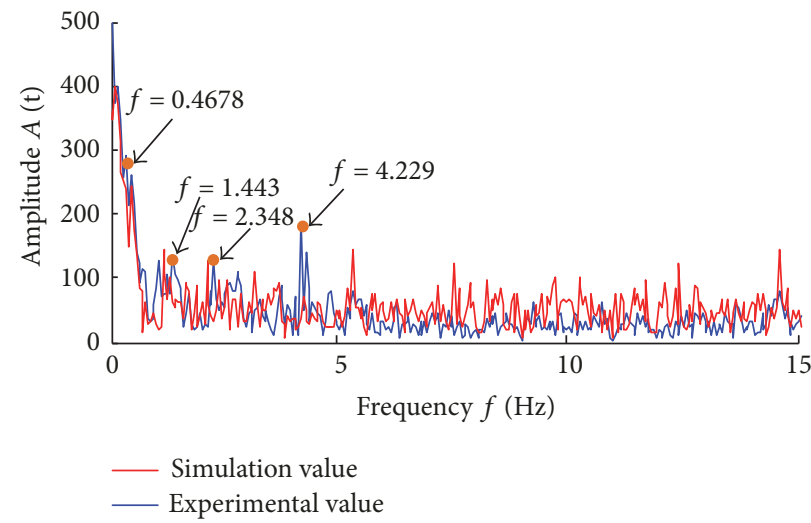

(d) Load of right guiding support plate along the $Z$ direction

FIGURE 10: Amplitude-frequency response curves for guiding support plate.

from $1.88 \mathrm{t}$ to $-1.85 \mathrm{t}$. Moreover, the mean force on the right guiding support plate decreases from $30.22 \mathrm{t}$ to $28.44 \mathrm{t}$, while that on the right plane support plate increases from $-2.67 \mathrm{t}$ to $-1.635 \mathrm{t}$

Figure 11(b) depicts changes in the mean force acting along the $Y$ direction on the two support plates during overhand mining at pitch angles varying between $0^{\circ}$ and $45^{\circ}$ and underhand stopping at pitch angles varying between $-45^{\circ}$ and $0^{\circ}$ at a constant roll angle. As can be seen from the figure, with increase in the overhand stopping angle from $0^{\circ}$ to $45^{\circ}$, the mean value of the force acting on the left guiding support plate increases from $4.06 \mathrm{t}$ to $4.89 \mathrm{t}$ while that acting on left plane support plate increases from $20.22 \mathrm{t}$ to $21.25 \mathrm{t}$. The mean force acting on the right guiding support plate decreases from $4.43 \mathrm{t}$ to $3.19 \mathrm{t}$, while that acting on the right plane support plate decreases from $7.7675 \mathrm{t}$ to $5.95 \mathrm{t}$. Meanwhile, with increase in the underhand stopping angle from $-45^{\circ}$ to $0^{\circ}$, the mean force acting on the left guiding support plate increases from $3.56 \mathrm{t}$ to $4.06 \mathrm{t}$, while that acting on the left plane support plate increases from $19.11 \mathrm{t}$ to $20.22 \mathrm{t}$. The mean force acting on the right guiding support plate decreases from $5.39 \mathrm{t}$ to $4.43 \mathrm{t}$, while that acting on the right plane supporting plate decreases from $8.74 \mathrm{t}$ to $7.675 \mathrm{t}$.

Figure 11(c) depicts changes in the mean force along the $Z$ direction on the two support plates during positive mining at roll angles varying from $0^{\circ}$ to $20^{\circ}$ degrees and negative mining at roll angles varying from $-20^{\circ}$ to $0^{\circ}$ with the pitch angle held constant. As can be seen from the figure, during positive roll mining with increase in roll angle from $0^{\circ}$ to $20^{\circ}$, the mean value of the force acting on the left guiding support plate increases from $29.825 \mathrm{t}$ to $31.97 \mathrm{t}$, while that acting on the left plane support plate increases from $-1.85 \mathrm{t}$ to $-0.6 \mathrm{t}$. The mean force acting on the right guiding support plate increases from $28.44 t$ to $29.59 t$, while that acting on the right plane support plate increases from $-1.635 \mathrm{t}$ to $-0.415 \mathrm{t}$. Meanwhile, with increase in roll angle from $-20^{\circ}$ to $0^{\circ}$ during the negative roll process, the mean force acting on the left guiding support plate increases from $27.87 \mathrm{t}$ to $29.825 \mathrm{t}$, while that acting on the left plane support plate increases from $-3.17 \mathrm{t}$ to $-1.85 \mathrm{t}$. The mean force acting on the right guiding support plate increases from $27.03 \mathrm{t}$ to $28.44 \mathrm{t}$, while that acting on the right plane support plate increases from $-2.37 \mathrm{t}$ to $-1.635 \mathrm{t}$.

Figure 11(d) depicts changes in the mean force acting along the $Y$ direction on the two support plates during positive and negative mining operations performed at roll angles varying between $0^{\circ}$ to $20^{\circ}$ and $-20^{\circ}$ to $0^{\circ}$, respectively, with the pitch angle held constant. As can be seen from the figure, during the positive roll mining process, with increase in roll angle from $0^{\circ}$ to $20^{\circ}$, the mean force acting on the left guiding support plate increases from $4.06 \mathrm{t}$ to $5.94 \mathrm{t}$, while 


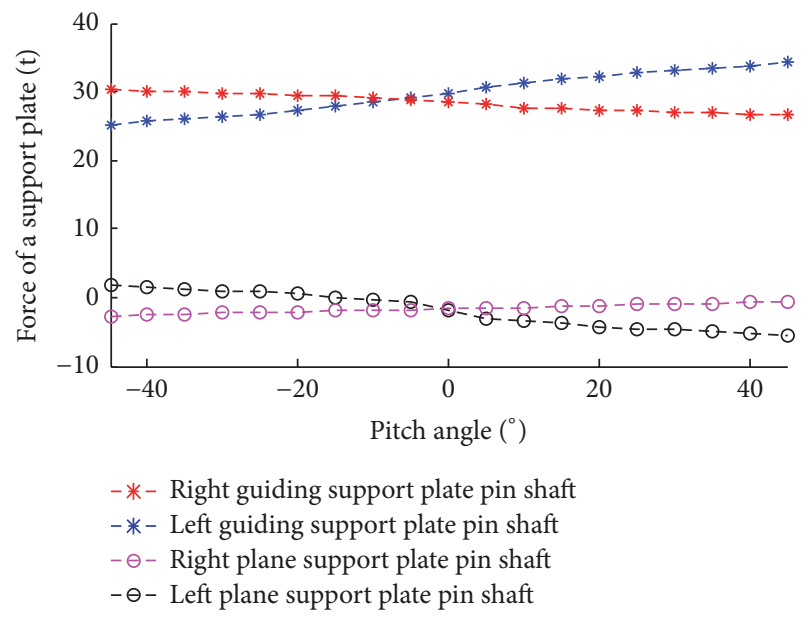

(a)

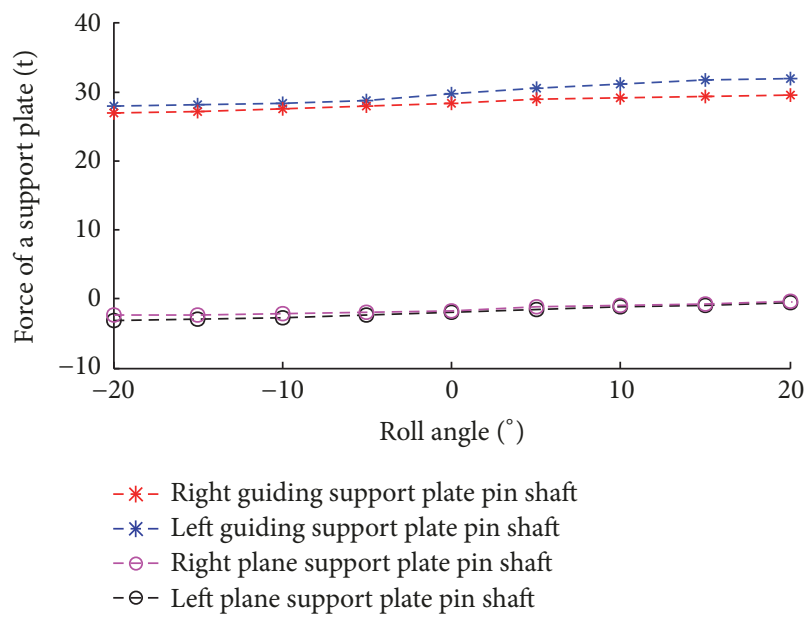

(c)

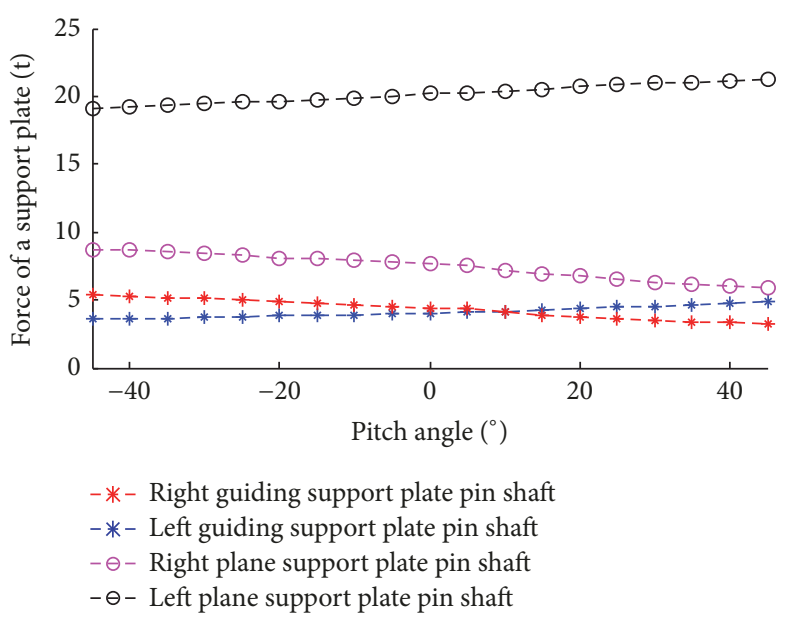

(b)

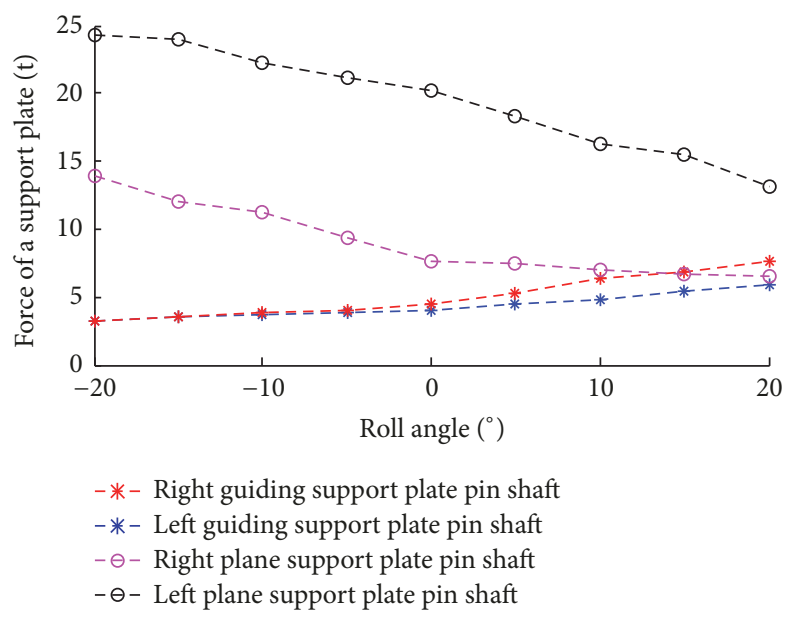

(d)

Figure 11: Variations in average forces acting on the support plate pin shafts with changes in pitch and roll angles. (a) Mean force along the $Z$ direction acting on support plate pin shafts corresponding to changes in positive pitch angle, (b) mean force along the $Y$ direction on support plate pin shafts corresponding to changes in negative pitch angle, (c) mean force along the $Z$ direction on support plate pin shafts corresponding to changes in positive roll angle, and (d) mean force along the $Y$ direction on support plate pin shafts corresponding to changes in negative roll angle.

that acting on the left plane support plate decreases from $20.22 \mathrm{t}$ to $13.12 \mathrm{t}$. The mean force acting on the right guiding support plate increases from $4.43 \mathrm{t}$ to $7.56 \mathrm{t}$, while that acting on the right plane support plate decreases from $7.675 \mathrm{t}$ to $6.59 \mathrm{t}$. Meanwhile, with increase in roll angle from $-20^{\circ}$ to $0^{\circ}$ during the negative roll mining process, the mean force acting on the left guiding support plate increases from $3.28 \mathrm{t}$ to $4.06 \mathrm{t}$, while that acting on the left plane support plate decreases from $24.32 \mathrm{t}$ to $20.22 \mathrm{t}$. The mean force acting on the right guiding support plate increases from $3.23 \mathrm{t}$ to $4.43 \mathrm{t}$, while that acting on the right plane support plate decreases from $13.85 \mathrm{t}$ to $7.65 \mathrm{t}$.

The range of magnitudes of the mean force acting on the support plates along the $Y$ and $Z$ directions under varying pitch and roll angles could be utilized as a base for further mechanical analysis and optimization of the shearer design.

\section{Lifetime Analysis and Structural Size Improvement of Guiding Support Plate}

Reference to Figure 11 and actual application of the proposed model in fully mechanized coal surface environment demonstrate that, under the effect of large shearer pitch angles, the guiding support plate is susceptible to breaking easily. Thus, the force curve, obtained at completion of the $50 \mathrm{~s}$ long simulation, corresponding to the left guiding support plate with mining operation performed at $50^{\circ}$ shearer pitch angle was considered as the load constraint of a loop. Subsequently, a lifetime analysis was performed using Ncode, the results of which are depicted in Figure 12(a). The figure indicates that the minimum lifetime position lies in the otic placode, and the corresponding loop number is $1.305 \times 106$. Because the period of each load loop is approximately $50 \mathrm{~s}$, if the shearer works for $16 \mathrm{~h} /$ day, the lifetime of left guiding support plate 


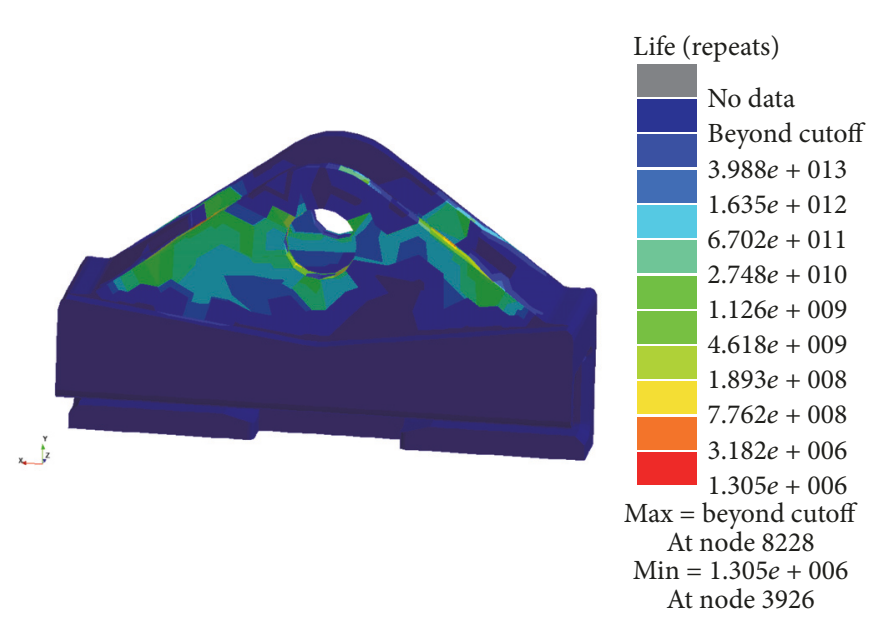

(a) Guiding support plate with original size

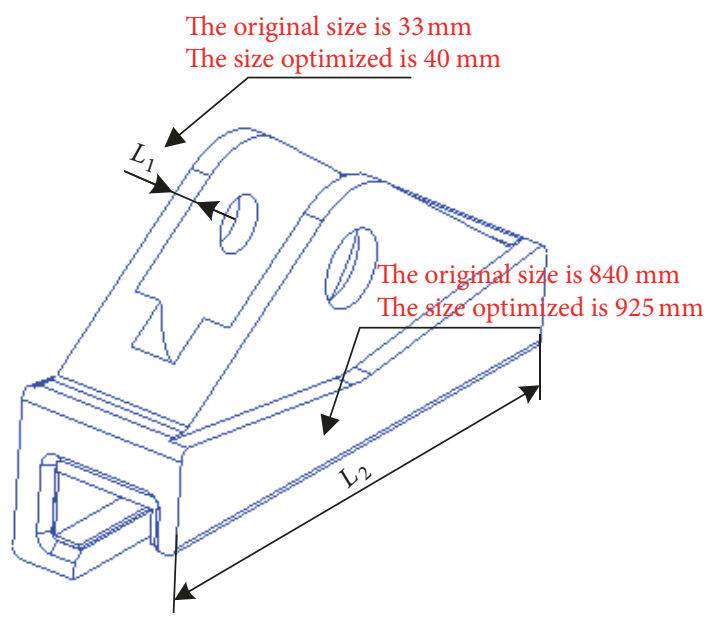

(b) Size improvement sketch of guiding support plate

(c) Guiding support plate with improved size

FIGURE 12: Lifetime analysis and comparison for guiding support plate.

would be approximately 1132 days. Typical designed production lifespan of coal seams in China is more than 20 years. Therefore, the lifespan of the guiding support plate is much shorter. As such, the otic placode thickness $L 1$ and guide plate thickness $L 2$ of the guiding support plate were optimized without influencing the matching performance of the shearer and scraper conveyor assemblies. The original and optimized sizes are depicted in Figure 12(b). The lifespan of the guiding support plate with the optimized size was analyzed using Ncode, and the result is depicted in Figure 12(c), which demonstrates that the minimum loop number of the weak spot has been increased to $3.290 \times 106$, which corresponds to roughly 1723 days more compared to the lifespan of the original guiding support plate. This translates to a 1.5 times increase in the original lifespan of the support plate.

\section{Conclusion}

Properties of a rigid-flexible coupling model of a shearer operating under the action of loads imposed during operation have been investigated by means of virtual simulations as well as experimental tests, and the following results have been obtained.
(1) When the operating phase of the drum switches from start-up to actual cutting, the average force acting on the left and right support plate pin shafts was observed to have reduced. Along the $Y$ direction, the average load on the left plane support plate pin shaft reduces from $22.52 \mathrm{t}$ to $19.74 \mathrm{t}$, while that on the right plane support plate pin shaft reduces from $18.09 \mathrm{t}$ to $10.07 \mathrm{t}$. Along the $Z$ direction, the mean load on the left plane support plate pin shaft reduces from $-4.21 \mathrm{t}$ to $-1.99 \mathrm{t}$ and that on the right plane support plate pin shaft reduces from $-3.7 \mathrm{t}$ to $-1.81 \mathrm{t}$. As the shearer drum is cut and lifting angle of right roller becomes large, the effect of the cutting load, traction load, and cutting resistance torque on the right roller causes the shearer to produce a backward overturning moment. As such, along the $Y$ direction, the force on the right side of the plane support plate pin shaft is of a smaller magnitude compared to that on the left side.

(2) Under the influence of the drum load, with the switch in operating phase of the drum, loads on the left and right sides of the guiding support plate pin shaft acting along the $Y$ direction are found to have reduced. Corresponding loads along $Z$ direction on the two sides of the same plate pin shaft demonstrate an increase in magnitude. Loads acting along the 
$Y$ direction on the two guiding support plate pin shafts appear as being negative on the curve; this indicates that the lower surface of the two guiding support plate pin shafts collides with the pin row during shearer operation.

(3) A comparison of experimental and simulation results demonstrates minimum (2.79\%) and maximum (16.3\%) errors incurred, while estimating the average load acting along the $Z$ direction on the right and left sides, respectively, of the plane support plate pin shaft. The actual error in terms of force magnitudes was approximately $0.28 \mathrm{t}$. This value is relatively small in comparison to the heavy loads acting on the shearer.

(4) Using the proposed simulation model, the effect of variations in pitch and roll angles, caused by changes in the direction of gravity forces, was investigated. Estimates of the average force acting on the support plates, obtained as a result of this analysis, could be utilized as a base for further mechanical analysis and optimization of the shearer design.

(5) Lastly, it has been demonstrated that the lifetime of guiding support plates could be extended by more than 1.5 times its original value through optimization of the otic placode and plate length.

\section{Conflicts of Interest}

The authors declare that they have no conflicts of interest.

\section{Acknowledgments}

This research was supported by three grants received from the National Natural Science Foundation of China (51404132, 51774162, and 51274112).

\section{References}

[1] A. B. Efremenkov, A. A. Khoreshok, S. A. Zhironkin, and A. V. Myaskov, "Coal mining machinery development as an ecological factor of progressive technologies implementation," IOP Conference Series: Earth and Environmental Science, vol. 50, no. 1, 2017.

[2] F. Simon, J. Barabady, and B. Abbas, "Availability analysis of the main conveyor in the Svea coal mine in Norway," International Journal of Mining Science and Technology, vol. 24, no. 5, pp. 587591, 2017.

[3] J. Korski, K. Tobór-Osadnik, and M. Wyganowska, "Mining machines effectiveness and OEE Indicator," IOP Conference Series: Materials Science and Engineering, vol. 268, 2017.

[4] S. Mandal, "Evaluation of reliability index of long wall equipment systems for production contingency," Mining Technology, vol. 78, no. 897, pp. 138-140, 1996.

[5] S. H. Hoseinie, M. Ataei, R. Khalokakaie, B. Ghodrati, and U. Kumar, "Reliability analysis of drum shearer machine at mechanized longwall mines," Journal of Quality in Maintenance Engineering, vol. 18, no. 1, pp. 98-119, 2012.

[6] P. Gong, J. Zhou, and Y. Lv, "Analysis of the damage reason of guide foot of MG375-type shearer," Coal Science \& Technology Magazine, vol. 4, pp. 9-10, 2006.

[7] R. Chai, W. Guo, and C. Yin, "Force and failure analysis of shearer guided sliding slippe," Coal Mine Machinery, vol. 36, no. 2, pp. 116-117, 2015.
[8] K. Liu, "Analysis on failure and improving of shearer haulage," Coal Mine Machinery, vol. 36, no. 01, pp. 281-282, 2015.

[9] G. Lang, X. Yuan, and W. Tuo, "Analysis of tooth-break fault on shearers walking wheel," Mechanical and Electrical, vol. 3, pp. 34-36, 2010.

[10] A. Zachura and R. Żuczek, "Innovative design of a longwall shearer's haulage system with highly loaded components of a tribological pair manufactured according to the precise casting technology," Solid State Phenomena, vol. 223, pp. 171-180, 2015.

[11] H. Chen, K. Zhang, S. Tian, J. Mao, and Q. Song, "Analysis on modelling and service life of pin row guide sliding shoes set on shearer under oblique cutting performances," Coal Science \& Technology Magazine, vol. 45, no. 4, pp. 82-88, 2017.

[12] C. Liu and S. Dai, "Mechanical modelling of whole doubledrum shearer and its solution," Journal of Heilongjiang Institute of Science \& Technology, vol. 22, no. 1, pp. 33-38, 2012.

[13] H. Chen, K. Zhang, Z. Yuan, and J. Mao, "Mechanics analyses of shearers based on resistance tests," Zhongguo Jixie Gongcheng, vol. 27, no. 19, pp. 2646-2651, 2016.

[14] C. Liu, D. Li, and S. Dai, "Influence of random load on mechanical properties of double-drum shearer," Mechanical and Electrical, vol. 6, pp. 45-48, 2012.

[15] L. Shen, Q. Li, Q. Lei, and H. Yan, "Structure improvement and finite element analysis of shearer guide skid shoe," Coal Mine Machinery, vol. 34, no. 10, pp. 165-166, 2013.

[16] M. Lu, "Finite element analysis of guided sliding boots in coal winning machine," Coal Mine Machinery, vol. 38, no. 4, pp. 5657, 2017.

[17] H. Chen, Y. Bai, J. Mao, and Q. Song, "7-DOF nonlinear vibration analysis of shearer under condition excitation," Jixie Qiangdu/Journal of Mechanical Strength, vol. 39, no. 1, pp. 1-6, 2017.

[18] B. Zhang, C. Liu, and H. Lin, "Analysis of force for shearer," Northeast Coal Technology, vol. 5, no. 10, pp. 40-42, 1999.

[19] C. Liu and C. Tian, "Solution of mechanical model of whole shearer based on least square principle," Journal of Liaoning Technical University: Natural Science, vol. 34, no. 4, pp. 505-510, 2015.

[20] Z. Wang, Kinematics analysis and strength study for haulage mechanism of drum shearer, Coal Science Research Institute, 2007.

[21] H. Chen, Y. Bai, J. Mao, and Q. Song, "Nonlinear vibration of shearer in walk plane under multiple excitation," Machine Design and Research, vol. 32, no. 2, pp. 166-170, 2016.

[22] J. Zhou, Y. Liu, S. Liu, and C. Du, "Characteristic analysis of dynamic meshing for shearer walking mechanism," Journal of Engineering Design, vol. 3, no. 20, pp. 230-237, 2013.

[23] D. Zhou, X.-F. Zhang, Z. Yang, and Y.-M. Zhang, "Vibration reliability analysis on tractive transmission system of shearer," Journal of the China Coal Society, vol. 40, no. 11, pp. 2546-2551, 2015.

[24] S. Liu and C. Luo, "Vibration experiment of shearer walking unit," Applied Mechanics and Materials, vol. 268, no. 1, pp. 12571261, 2013.

[25] H. Liu, L. Wang, S. Ge, S. Cao, J. Jin, and J. Gao, "Optimization of shearer sliding boots by plasma cladding with Cr4MnTi," International Journal of Mining Science and Technology, vol. 21, no. 6, pp. 877-880, 2011.

[26] B. Hong and J. Gong, "Tribological properties of Fe-Cr-B alloy for sliding boot in coal mining machine under dry sliding condition," Industrial Lubrication and Tribology, vol. 69, no. 02, pp. 142-148, 2017. 
[27] K. Zhou, J. Lu, Y. Hou, Y. Wei, L. Meng, and Y. Sai, "Dynamics modeling and parameter identification of leaf spring based on Recurdyn," Journal of Mechanical Engineering, vol. 50, no. 4, pp. 128-134, 2014.

[28] P. Mishra, M. Kumar, S. Kumar, and P. Mandal, "Wireless realtime sensing platform using vibrating wire-based geotechnical sensor for underground coal mines," Sensors \& Actuators A Physical, vol. 269, pp. 212-217, 2018.

[29] H. Lee, J. Kim, K. Sho, and H. Park, "A wireless vibrating wire sensor node for continuous structural health monitoring," Smart Materials \& Structures, vol. 19, no. 19, 2010. 


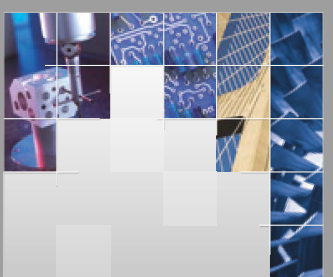

\section{Enfincering}
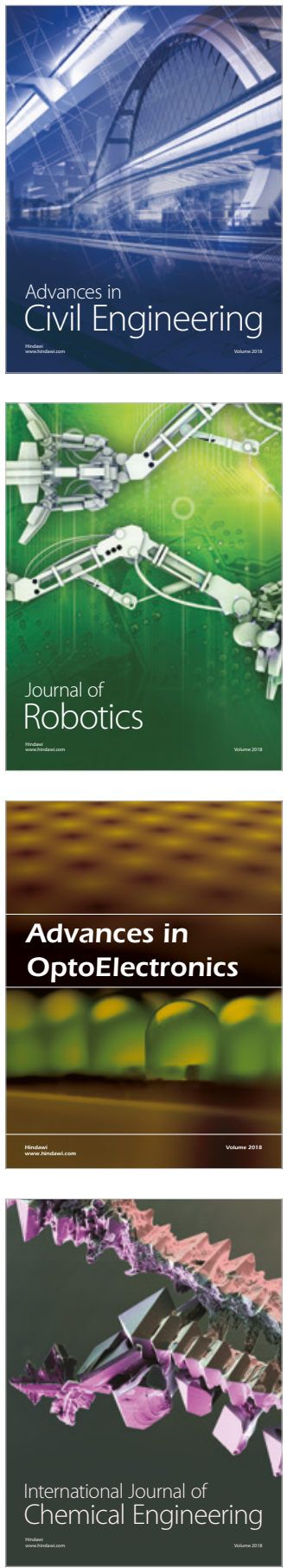

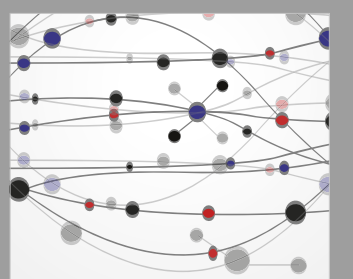

\section{Rotating \\ Machinery}

The Scientific World Journal

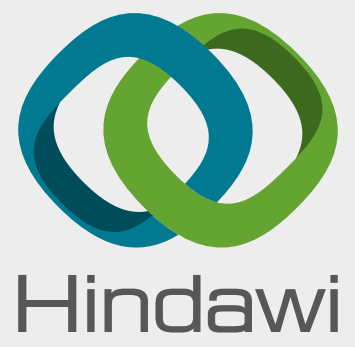

Submit your manuscripts at

www.hindawi.com
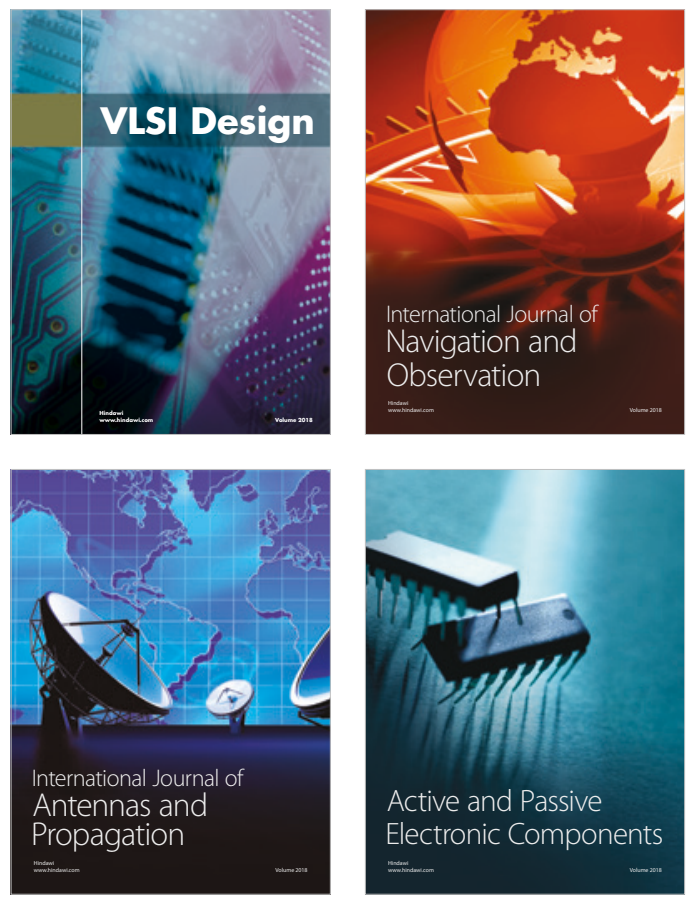
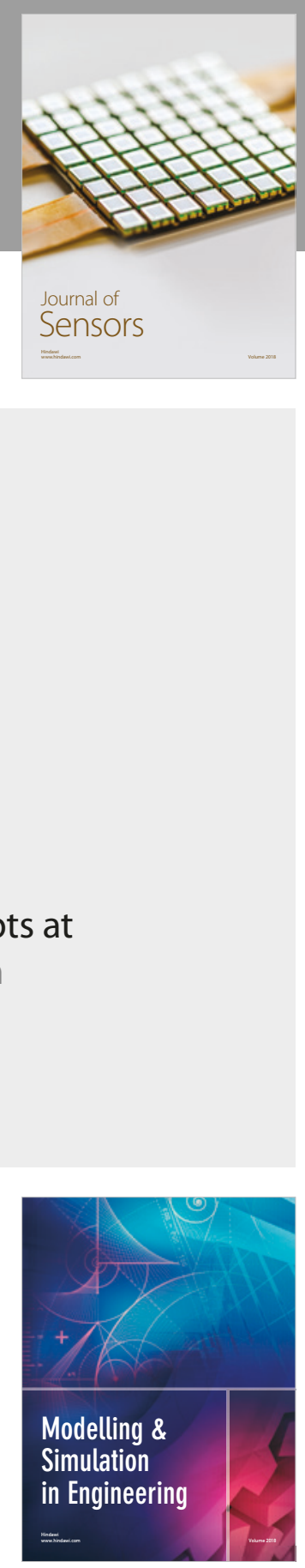

\section{Advances \\ Multimedia}
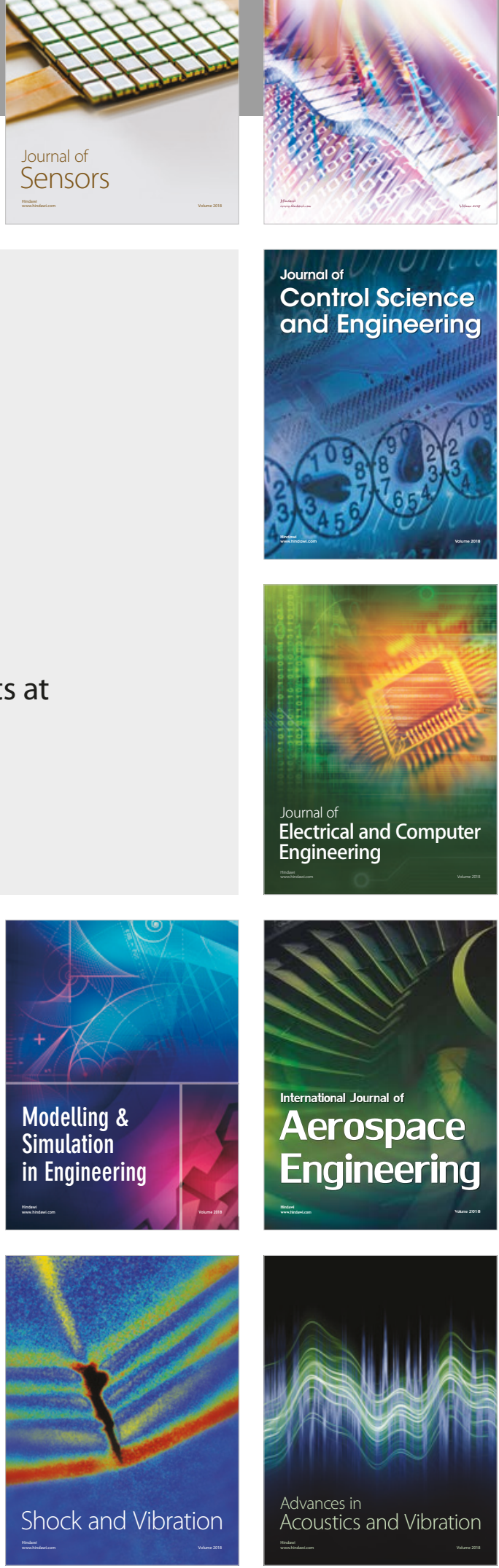